Chapter 1

\title{
Soil Contamination, Risk Assessment and Remediation
}

\author{
Muhammad Aqeel Ashraf, Mohd. Jamil Maah and \\ Ismail Yusoff
}

Additional information is available at the end of the chapter

http://dx.doi.org/10.5772/57287

\section{Introduction}

Environment pollution is a burning topic of the day. Air, water and soil are being polluted alike. Soil being a "universal sink" bears the greatest burden of environmental pollution. It is getting polluted in a number of ways. There is urgency in controlling the soil pollution in order to preserve the soil fertility and increase the productivity. Pollution may be defined as an undesirable change in the physical, chemical and biological characteristics of air, water and soil which affect human life, lives of other useful living plants and animals, industrial progress, living conditions and cultural assets. A pollutant is something which adversely interfere with health, comfort, property or environment of the people. Generally most pollutants are introduced in the environment by sewage, waste, accidental discharge or else they are byproducts or residues from the production of something useful. Due to this our precious natural resources like air, water and soil are getting polluted.

The basis of agriculture is Soil. All crops for human food and animal feed depend upon it. We are losing this important natural resource by the accelerated erosion 10 some extent. In addition to this the enormous quantities of man-made waste products, sludge and other product" from new waste treatment plants even polluted water are also causing or leading to soil pollution. In order to preserve the fertility and the productivity of the soil, control measures are to be taken in a herculean manner, thereby improving the health of all living beings.

Assessing the ecological risk of contaminated soil, pesticide application, sewage sludge amendment, and other human activities leading to exposure of the terrestrial environment to hazardous substances is a complicated task with numerous associated problems. Not only is terrestrial ecological risk assessment a relatively new field of science that has developed rapidly only since the mid-1980s, but it is also complicated by the fact that soil, in contrast to most aquatic environments, is very often on private lands and traded as real estate. Profes- 
sional and economic divergence between the interests of scientists, stakeholders, authorities, engineers, managers, lawyers, nongovernment organizations (NGOs) and regulators is therefore not unusual. Even neglecting those aspects, a number of unresolved problems exist in the way we currently assess risk and manage the impact of anthropogenic substances in the terrestrial environment.

This chapter does not intend to present a comprehensive review of all published data from ecological studies at contaminated sites. Instead, the observations from all case studies are used in the discussion and form the basis for the final conclusion. In each case, we try to answer the following questions:

1. What is soil pollution and how it occurs?

2. How to determine the ecological risk assessment of the soil?

3. To what extent do soil screening levels (over)estimate risk?

4. Do bioassays represent a more realistic risk estimate?

5. Is it possible to make sound field surveys, or do we lack suitable reference situations?

6. What are the possible soil management methods for the polluted soils?

\section{Soil pollution}

Soil pollution is defined as the build-up in soils of persistent toxic compounds, chemicals, salts, radioactive materials, or disease causing agents, which have adverse effects on plant growth and animal health [1].

Soil is the thin layer of organic and inorganic materials that covers the Earth's rocky surface. The organic portion, which is derived from the decayed remains of plants and animal, is concentrated in the dark uppermost topsoil. The inorganic portion made up of rock fragments, was formed over thousands of years by physical and chemical weathering of bedrock. Productive soils are necessary for agriculture to supply the world with sufficient food [2].

There are many different ways that soil can become polluted, such as:

- Seepage from a landfill

- Discharge of industrial waste into the soil

- Percolation of contaminated water into the soil

- Rupture of underground storage tanks

- Excess application of pesticides, herbicides or fertilizer

- Solid waste seepage

The most common chemicals involved in causing soil pollution are: 
- Petroleum hydrocarbons

- Heavy metals

- Pesticides

- Solvents

\subsection{Inorganic toxic compounds}

Inorganic residues in industrial waste cause serious problems as regards their disposal. They contain metals which have high potential for toxicity. Industrial activity also emits large amounts of arsenic fluorides and sulphur dioxide $\left(\mathrm{SO}_{2}\right)$ [3]. Fluorides are found in the atmosphere from superphosphate, phosphoric acid, aluminium, steel and ceramic industries. Sulphur dioxide emitted by factories and thermal plants may make soils very acidic. These metals cause leaf injury and destroy vegetation.

Copper, mercury, cadmium, lead, nickel, arsenic are the elements which can accumulate in the soil, if they get entry either through sewage, industrial waste or mine washings. Some of the fungicides containing copper and mercury also add to soil pollution. Smokes from automobiles contain lead which gets adsorbed by soil particles and is toxic to plants. The toxicity can be minimized by building up soil organic matter, adding lime to soils and keeping the soil alkaline [4].

\subsection{Organic wastes}

Organic wastes of various types cause pollution hazards. Domestic garbage, municipal sewage and industrial wastes when left in heaps or improperly disposed seriously affect health of human beings, plants and animals [5-7]. Organic wastes contain borates, phosphates, detergents in large amounts. If untreated they will affect the vegetative growth of plants. The main organic contaminants are phenols and coal.

Asbestos, combustible materials, gases like methane, carbon dioxide, hydrogen sulphide, carbon monoxide, sulphur dioxide, petrol are also contaminants. The radioactive materials like uranium, thorium, strontium etc. also cause dangerous soil pollution. Fallout of strontium mostly remains on the soil and is concentrated in the sediments [8]. Decontamination procedures may include continuous cropping and use of chelate amendments. Other liquids wastes like sewage, sewage sludge, etc. are also important sources of soil problems.

a. Sewage and sewage sludge

Soil pollution is often caused by the uncontrolled disposal of sewage and other liquid wastes resulting from domestic uses of water, industrial wastes containing a variety of pollutants, agricultural effluents from animal husbandry and drainage of irrigation water and urban runoff [9-10]. Irrigation with sewage water causes profound changes in the irrigated soils. Amongst various changes that are brought about in the soil as an outlet of sewage irrigation include physical changes like leaching, changes in humus content, and porosity etc., chemical changes like soil reaction, base exchange status, salinity, quantity and availability of nutrients 
like nitrogen, potash, phosphorus, etc. Sewage sludges pollute the soil by accumulating the metals like lead, nickel, zinc, cadmium, etc. This may lead to the phytoxicity of plants.

b. Heavy metal pollutants

Heavy metals are elements having a density greater than five in their elemental form. They mostly find specific absorption sites in the soil where they are retained very strongly either on the inorganic or organic colloids. They are widely distributed in the environment, soils, plants, animals and in their tissues. These are essential for plants and animals in trace amounts. Mainly urban and industrial aerosols, combustion of fuels, liquid and solid from animals and human beings, mining wastes, industrial and agricultural chemicals etc. are contributing heavy metal pollution. Heavy metals are present in all uncontaminated soils as the result of weathering from their parent materials. Concentration of heavy metals in soils and plants is given in Table 1.

\begin{tabular}{lllll}
\hline SI.No & Heavy metal & Hithosphere & Soil range & Plants \\
\hline $\mathbf{1}$ & Cadmium (Cd) & 0.2 & $0.01-0.7$ & $0.2-0.8$ \\
\hline $\mathbf{2}$ & Cobalt (Co) & 40 & $1-40$ & $0.05-0.5$ \\
\hline $\mathbf{4}$ & Chromium (Cr) & 200 & $5-3000$ & $0.2-1.0$ \\
\hline $\mathbf{5}$ & Copper (Cu) & 70 & $2-100$ & $4-15$ \\
\hline $\mathbf{6}$ & Iron (Fe) & 50,000 & $7000-5,50,000$ & 140 \\
\hline $\mathbf{7}$ & Mercury (Hg) & 0.5 & $0.01-0.3$ & 0.015 \\
\hline $\mathbf{8}$ & Manganese (Mn) & 1000 & $100-4000$ & $15-100$ \\
\hline $\mathbf{9}$ & Molybdenum (Mo) & Nickel (Ni) & 100 & $1-10$ \\
\hline $\mathbf{1 0}$ & Lead (Pb) & 16 & $10-1000$ & 1 \\
\hline $\mathbf{1 1}$ & Tin (Sn) & 40 & $2-200$ & $0.1-10$ \\
\hline $\mathbf{1 2}$ & Zinc (Zn) & 80 & $10-300$ & 0.3 \\
\hline
\end{tabular}

Table 1. Heavy metal concentration in the hithosphere, soils and plants (Ug/gm dry matter)

In agricultural soils, however, the concentration of one or more of these elements may be significantly increased in several ways, like through applications of chemicals, sewage sludge, farm slurries, etc. Increased doses of fertilizers, pesticides or agricultural chemicals, over a period, add heavy metals to soils which may contaminate them. Certain phosphatic fertilizers frequently contain trace amounts of cadmium which may accumulate in these soils. Likewise, some fertilizers when applied to soils, they add certain heavy metals which are given in Table 2 .

The range of heavy metal contents in sludges is given in Table 3. 


\begin{tabular}{|c|c|c|c|c|c|c|c|c|c|}
\hline SI.No & Fertilizer & Co & $\mathrm{Cr}$ & $\mathrm{Cu}$ & Mn & Mo & $\mathrm{Ni}$ & $\mathrm{Pb}$ & $\mathrm{Zn}$ \\
\hline 1 & Nitrochalk & - & - & 22 & 24 & - & 2 & - & 15 \\
\hline 2 & Calcium & 0.1 & Traces & Traces & Traces & - & - & - & 1 \\
\hline 3 & Nitrate & - & - & To 10 & To 5 & - & - & - & - \\
\hline 4 & $\begin{array}{l}\text { Ammonium } \\
\text { sulphate }\end{array}$ & $<5$ & $<5$ & 0.800 & 0.80 & $\begin{array}{l}<0.05 \text { to } \\
0.22\end{array}$ & $<5$ & $\begin{array}{l}\text { Traces to } \\
200\end{array}$ & 0.800 \\
\hline 5 & Super phosphate & $0.02-13$ & $0-1000$ & $\begin{array}{l}\text { Traces to } \\
1000\end{array}$ & $\begin{array}{l}\text { Traces to } \\
2842\end{array}$ & Traces to 35 & $\begin{array}{l}\text { Traces to } \\
32\end{array}$ & $\begin{array}{l}\text { Traces to } \\
92\end{array}$ & $70-3000$ \\
\hline 6 & $\begin{array}{l}\text { Potassium } \\
\text { chloride }\end{array}$ & 001 & - & $0-10$ & Traces-8 & $<0.05$ & $<1$ & $<1$ & $0-3$ \\
\hline 7 & $\begin{array}{l}\text { Potassium } \\
\text { sulphate }\end{array}$ & $<5$ & $<5$ & $0-300$ to 80 & $\begin{array}{l}\text { Traces to. } \\
33\end{array}$ & 0.09 & $<5$ & $<50$ & $<50$ \\
\hline
\end{tabular}

Table 2. Heavy metal content of fertilizers (ug/gm)

\begin{tabular}{lll}
\hline Sl.No & Heavy metal & Range $(\mathbf{p p m})$ \\
\hline $\mathbf{1}$ & Cadmium & $<60-1500$ \\
\hline $\mathbf{2}$ & Cobalt & $2-260$ \\
\hline $\mathbf{3}$ & Chromium & $40-8800$ \\
\hline $\mathbf{5}$ & Copper & $200-8000$ \\
\hline $\mathbf{6}$ & Iron & $6000-62,000$ \\
\hline $\mathbf{7}$ & Manganese & $150-2500$ \\
\hline $\mathbf{8}$ & Molybdenum & $2-30$ \\
\hline $\mathbf{9}$ & Nickel & $20-5300$ \\
\hline $\mathbf{1 0}$ & Lead & $120-3000$ \\
\hline
\end{tabular}

Table 3. Heavy metal contents in sludges (ppm)

The fate of heavy metals in soil will be controlled by physical and biological processes acting within the soil. Metal ions enter the soil solution from these various forms of combination in different rates they may either remain in solution or pass into the drainage water or be taken up by plants growing on the soil or be retained by the soil in sparingly soluble or insoluble forms. The organic matter of these soil have great affinity to heavy metals cations which form stable complexes thereby leading to reduced nutrient content [11-12].

\subsection{Organic pesticides}

Pesticides are quite frequently used to -control several types of pests now-a-days. Pesticides may exert harmful effects to micro-organisms, as a result of which plant growth may be 
affected. Pesticides which are not rapidly decomposed may create such problems. Accumulation is residues of pesticides in higher concentrations are toxic. Pesticides persistence in soil and movement into water streams may also lead to their entry into foods and create health hazards. Pesticides particularly aromatic organic compounds are not degraded rapidly and therefore, have a long persistence time which can be seen in Table 4.

\begin{tabular}{lll}
\hline SI.No & Pesticide & Persistence time \\
\hline $\mathbf{1}$ & BHC & 11 yrs \\
\hline $\mathbf{2}$ & DDT & 10 yrs \\
\hline $\mathbf{3}$ & $2,4-D$ & $2-8$ weeks \\
\hline $\mathbf{4}$ & Aldrin & 9 yrs \\
\hline $\mathbf{6}$ & Diuron & 16 months \\
\hline $\mathbf{7}$ & Atrazine & 18 months \\
\hline $\mathbf{8}$ & Siwazine & 17 months \\
\hline $\mathbf{9}$ & Chlordane & 12 yrs \\
\hline
\end{tabular}

Table 4. Persistence time for some selected pesticides

Mercury, cadmium and arsenic are common constituents of pesticides and all these heavy metals are toxic. At present DDT and a number of organochlorine compounds used as pesticides have been declared harmful and banned in U.S.A. and England [13-14]. It is due to the persistence of their residues in soils for considerable time without losing their toxicity. This has led to higher concentration of these pesticides in vegetation, in animal flesh and milk. Eventually man has been affected. In view of their demerits, organochlorines have been replaced by organophosphate pesticides which are more toxic, but do not leave any residue. They do not pollute the soil. The rodenticides too add to soil pollution. A major method of checking this pesticidal pollution is to increase the organic matter content of the sol and choose such pesticides which are non-persistent and leave no harmful residue.

\subsection{Types of soil pollution}

- Agricultural Soil Pollution

i. pollution of surface soil

ii. pollution of underground soil

- Soil pollution by industrial effluents and solid wastes

i. pollution of surface soil

ii. disturbances in soil profile 
- Pollution due to urban activities

i. pollution of surface soil

ii. pollution of underground soil

\subsection{Sources of soil pollution}

The sources which pollute the soil are twofold: Agricultural sources and non-agricultural sources. Figure 1 shows the different sources for the soil pollution.

a. Agricultural sources

Soil pollution comes from different sources including agriculture and animal husbandry. Some of the agricultural practices lead to soil pollution. They are animal wastes, use of long lived pesticides, herbicides, fungicides, nematocides, etc. fertilizers and some agricultural practices.

b. Non-agricultural sources

Soil pollution by non-agricultural sources is usually the direct result of urban sprawl caused by rapidly increasing population and a rapidly per capita output of waste related to our modem way of life. Its materials that find their entry into the soil system have long persistence and accumulate in toxic concentration and thus become sources of pollution. Some of those most important soil pollutants are inorganic toxic compounds.

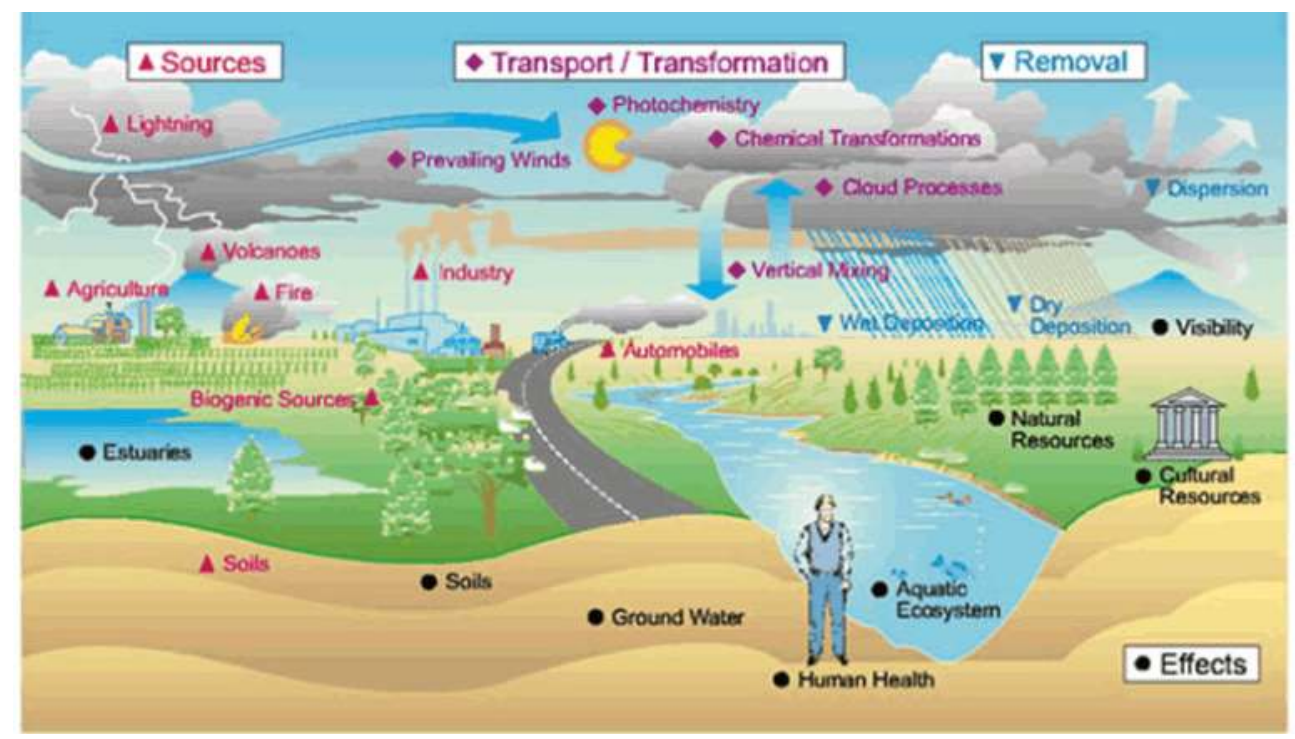

Figure 1. Sources of Soil Pollution [5] 


\subsection{Causes of soil pollution}

Soil pollution is caused by the presence of man-made chemicals or other alteration in the natural soil environment. This type of contamination typically arises from the rupture of underground storage links, application of pesticides, and percolation of contaminated surface water to subsurface strata, oil and fuel dumping, leaching of wastes from landfills or direct discharge of industrial wastes to the soil. The most common chemicals involved are petroleum hydrocarbons, solvents, pesticides, lead and other heavy metals. This occurrence of this phenomenon is correlated with the degree of industrialization and intensities of chemical usage. A soil pollutant is any factor which deteriorates the quality, texture and mineral content of the soil or which disturbs the biological balance of the organisms in the soil. Pollution in soil has adverse effect on plant growth.

Pollution in soil is associated with

- Indiscriminate use of fertilizers

- Indiscriminate use of pesticides, insecticides and herbicides

- Dumping of large quantities of solid waste

- Deforestation and soil erosion

a. Indiscriminate use of fertilizers

Oxygen from air and water but other necessary nutrients like nitrogen, phosphorus, potassium, calcium, magnesium, sulfur and more must be obtained from the soil. Farmers generally use fertilizers to correct soil deficiencies. Fertilizers contaminate the soil with impurities, which come from the raw materials used for their manufacture. Mixed fertilizers often contain ammonium nitrate $\left(\mathrm{NH}_{4} \mathrm{NO}_{3}\right)$, phosphorus as $\mathrm{P}_{2} \mathrm{O}_{5}$, and potassium as $\mathrm{K}_{2} \mathrm{O}$. For instance, As, $\mathrm{Pb}$ and $\mathrm{Cd}$ present in traces in rock phosphate mineral get transferred to super phosphate fertilizer. Since the metals are not degradable, their accumulation in the soil above their toxic levels due to excessive use of phosphate fertilizers becomes an indestructible poison for crops. The over use of NPK fertilizers reduce quantity of vegetables and crops grown on soil over the years. It also reduces the protein content of wheat, maize, grams, etc., grown on that soil. The carbohydrate quality of such crops also gets degraded [15]. Excess potassium content in soil decreases Vitamin $C$ and carotene content in vegetables and fruits. The vegetables and fruits grown on over fertilized soil are more prone to attacks by insects and disease.

b. Indiscriminate use of pesticides, insecticides and herbicides

Plants on which we depend for food are under attack from insects, fungi, bacteria, viruses, rodents and other animals, and must compete with weeds for nutrients. To kill unwanted populations living in or on their crops, farmers use pesticides. The first widespread insecticide use began at the end of World War II and included DDT (dichlorodiphenyltrichloroethane) and gammaxene. Insects soon became resistant to DDT and as the chemical did not decompose readily, it persisted in the environment. Since it was soluble in fat rather than water, it biomagnified up the food chain and disrupted calcium metabolism in birds, causing eggshells to be thin and fragile. As a result, large birds of prey such as the brown pelican, ospreys, falcons 
and eagles became endangered. DDT has been now been banned in most western countries. Ironically many of them including USA, still produce DDT for export to other developing nations whose needs outweigh the problems caused by it [16].

c. Dumping of solid wastes

In general, solid waste includes garbage, domestic refuse and discarded solid materials such as those from commercial, industrial and agricultural operations. They contain increasing amounts of paper, cardboards, plastics, glass, old construction material, packaging material and toxic or otherwise hazardous substances. Since a significant amount of urban solid waste tends to be paper and food waste, the majority is recyclable or biodegradable in landfills. Similarly, most agricultural waste is recycled and mining waste is left on site. The portion of solid waste that is hazardous such as oils, battery metals, heavy metals from smelting industries and organic solvents are the ones we have to pay particular attention to. These can in the long run, get deposited to the soils of the surrounding area and pollute them by altering their chemical and biological properties [17].

\section{d. Deforestation}

Soil Erosion occurs when the weathered soil particles are dislodged and carried away by wind or water. Deforestation, agricultural development, temperature extremes, precipitation including acid rain, and human activities contribute to this erosion. Humans speed up this process by construction, mining, cutting of timber, over cropping and overgrazing. It results in floods and cause soil erosion. Forests and grasslands are an excellent binding material that keeps the soil intact and healthy. They support many habitats and ecosystems, which provide innumerable feeding pathways or food chains to all species. Their loss would threaten food chains and the survival of many species. During the past few years quite a lot of vast green land has been converted into deserts. The precious rain forest habitats of South America, tropical Asia and Africa are coming under pressure of population growth and development (especially timber, construction and agriculture). Many scientists believe that a wealth of medicinal substances including a cure for cancer and aids, lie in these forests. Deforestation is slowly destroying the most productive flora and fauna areas in the world, which also form vast tracts of a very valuable sink for $\mathrm{CO}_{2}[18]$.

e. Pollution due to urbanization

Pollution of surface soils materials (like vegetables, animal wastes, papers, wooden pieces, carcasses, plant twigs, leaves, cloth wastes as well as sweepings) and many non-biodegradable materials (such as plastic bags, plastic bottles, plastic wastes, glass bottles, glass pieces, stone / cement pieces) [19-20]. On a rough estimate Indian cities are producing solid city wastes to the tune of 50,000 - 80,000 metric tons every day. If left uncollected and decomposed, they are a cause of several problems such as;

- Clogging of drains: Causing serious drainage problems including the burst / leakage of drainage lines leading to health problems. 
- Barrier to movement of water: Solid wastes have seriously damaged the normal movement of water thus creating problem of inundation, damage to foundation of buildings as well as public health hazards.

- Foul smell: Generated by dumping the wastes at a place.

- Increased microbial activities: Microbial decomposition of organic wastes generate large quantities of methane besides many chemicals to pollute the soil and water flowing on its surface

- When such solid wastes are hospital wastes they create many health problems: As they may have dangerous pathogen within them besides dangerous medicines, injections.

f. Pollution of underground soil

Underground soil in cities is likely to be polluted by

- Chemicals released by industrial wastes and industrial wastes

- Decomposed and partially decomposed materials of sanitary wastes

Many dangerous chemicals like cadmium, chromium, lead, arsenic, selenium products are likely to be deposited in underground soil. Similarly underground soils polluted by sanitary wastes generate many harmful chemicals. These can damage the normal activities and ecological balance in the underground soil

\subsection{Effects of soil pollution}

a. Agricultural

- Reduced soil fertility

- Reduced nitrogen fixation

- Increased erodibility

- Larger loss of soil and nutrients

- Deposition of silt in tanks and reservoirs

- Reduced crop yield

- Imbalance in soil fauna and flora

b. Industrial

- Dangerous chemicals entering underground water

- Ecological imbalance

- Release of pollutant gases

- Release of radioactive rays causing health problems

- Increased salinity 
- Reduced vegetation

c. Urban

- Clogging of drains

- Inundation of areas

- Public health problems

- Pollution of drinking water sources

- Foul smell and release of gases

- Waste management problems

d. Environmental

- Soil becomes unavailable to grow food

- If contaminated soil is used to grow food, the land will usually produce lower yields

- Can cause even more harm because a lack of plants on the soil will cause more erosion

- The pollutants will change the makeup of the soil and the types of microorganisms that will live in it.

- Thus it's possible for soil pollution to change whole ecosystems

\subsection{Control of soil pollution}

The following steps have been suggested to control soil pollution. To help prevent soil erosion, we can limit construction in sensitive area. In general we would need less fertilizer and fewer pesticides if we could all adopt the three R's: Reduce, Reuse, and Recycle. This would give us less solid waste.

a. Extraction and separation techniques

In solvent extraction, the contaminated \& oil is mixed with an extracting agent in general (an aqueous solution but preferably an organic solvent). Potential applications include the removal of metals such as cadmium, copper, zinc, nickel, chromium, arsenic, antimony and lead using a mineral solution, zinc lead, organo-metallic compounds and some cyanides using sodium hydroxide solution. Hydrocarbons and halogenated hydrocarbons can also be removed [21]. Contamination is often preferentially present in the finer or coarser fraction of the soil or the organic components (ex. humus), contamination can therefore, be removed in some cases using a process which separates the soil into fractions on the basis of specific gravity or particle size or settling velocity.

b. Thermal methods

In thermal methods, there are two ways of heat treatment; removal of contaminants by evaporation either by direct heat transfer from heated air or an open flame or by indirect heat transfer, and destruction of the contaminants directly or indirectly at an appropriate temper- 
ature. The gas leaving the heating appliance must be treated to destroy or remove any contaminants or unwanted products of combustion. A related process is stream stripping in which steam is injected into soil to aid evaporation of relatively volatile contaminants which may be water soluble or insoluble.

c. Chemical methods

Treatment of the soil in suspension in a suitable liquid and without sludging is the two possible methods. In these, intimate, contact between soil and chemical is essential and should be frequently done so that the process of detoxification is complete.

d. Microbial treatment methods

The microbial treatment methods appear to be more promising which can deal with whole range of organic contaminants including phenol, polychlorinated hydrocarbons, oil and oil products, dioxins, etc. There are two different ways of approaching the problems.

1. A community of microbes already existing on the site is collected and cultured in the laboratory.

2. Strains of microbes are developed in the laboratory that is capable of metabolizing particular chemicals.

Excavation of the soil prior to treatment offers the greatest scope for creating optimum conditions. The excavated soil can be placed on thin layers to various depth using standard earth moving techniques and microbes and nutrients applied using standard agricultural techniques such as fertilizing, ploughing, harrowing, etc.

e. Reducing chemical fertilizer and pesticide use

Applying bio-fertilizers and manures can reduce chemical fertilizer and pesticide use. Biological methods of pest control can also reduce the use of pesticides and thereby minimize soil pollution.

\section{f. Reusing of materials}

Materials such as glass containers, plastic bags, paper, cloth etc. can be reused at domestic levels rather than being disposed, reducing solid waste pollution.

g. Recycling and recovery of materials

This is a reasonable solution for reducing soil pollution. Materials such as paper, some kinds of plastics and glass can and are being recycled. This decreases the volume of refuse and helps in the conservation of natural resources. For example, recovery of one tonne of paper can save 17 trees.

\section{h. Reforesting}

Control of land loss and soil erosion can be attempted through restoring forest and grass cover to check wastelands, soil erosion and floods. Crop rotation or mixed cropping can improve the fertility of the land. 


\section{i. Solid waste treatment}

Proper methods should be adopted for management of solid waste disposal. Industrial wastes can be treated physically, chemically and biologically until they are less hazardous. Acidic and alkaline wastes should be first neutralized; the insoluble material if biodegradable should be allowed to degrade under controlled conditions before being disposed. As a last resort, new areas for storage of hazardous waste should be investigated such as deep well injection and more secure landfills. Burying the waste in locations situated away from residential areas is the simplest and most widely used technique of solid waste management.

\subsection{Soil monitoring}

The main objective of soil monitoring is to prevent and mitigate contamination by substances with the potential to exert an adverse effect on the soil itself, and on air, water and organisms that may contact the soil. Soil monitoring, within the approvals program, is directed primarily to the assessment of contaminants that have been released to the soil surface. Thus, subsurface facilities are generally not the reason for soil monitoring, but may be the reason for groundwater monitoring [22]. However, where soil contamination is known or suspected to originate from subsurface sources such as underground tanks or pipes, an assessment will be required. Where the above considerations indicate soil monitoring is required as a condition of an Approval, the proponent is required to carry out the following, as specified in the Soil Monitoring Directive: > prepare a soil monitoring proposal; > execute the approved soil monitoring plan; > interpret and report the results of the soil monitoring; and > prepare and execute a soil management plan where indicated by the results of soil monitoring. This guideline provides a background for the soil monitoring program and a description of soil management program requirements.

a. Legislative background

The soil monitoring program mostly developed under the Environmental Protection in support of the following principles: > development must be sustainable, meaning that the use of resources and the environment today must not impair prospects for their use by future generations; > the environmental impact of development must be prevented or mitigated; > polluters should bear the responsibility of paying for the costs of their actions; > remediation costs should be incorporated into financial planning so that adequate funds are available for site remediation and planners can know the true costs and benefits of source reduction programs. Recognizing that under the environmental protection is a shared responsibility, it follows that both the approval holder and the Department must have a means to assess environmental performance with respect to the above principles and requirements.

b. Soil quality standards

Environmental Protection expects that approval holders will manage their operations to prevent substance releases to soil. Substance releases to soil do occur, however, and contaminants are often present above background concentrations at industrial facilities. In view of this, Environmental Protection should have soil quality standards to guide assessment and 
remediation of soil contamination. Facilities that are currently uncontaminated have the opportunity to maintain conditions that allow unrestricted land-use. For these facilities, the minimum standards will be determined by the Tier I criteria or equivalent objectives. Older facilities, however, were often operated under different standards and environmental management practices than are currently acceptable.

\subsection{Soil pollution risks}

There is an increasing use of risk-oriented policies to deal with the local effects of soil pollution. The risks that such policies deal with are: human health risks and can also include ecotoxicological risks. These risks are expressed in terms of negative effects and chances between 0 and 1 that such negative effects will occur. Examples of areas where risk-oriented policies are applied to soil pollution include the United States of America [23], Canada [24] and countries in the European Union [25]. Historically, these risk oriented policies have followed the abandonment of policies aimed at restoring soils to their original 'clean' state.

Risk-based criteria or standards, developed in the framework of risk oriented policies, are applied to risks estimated with deterministic methodologies, following the steps of hazard characterization, appraisal of exposure and risk characterization, while using exposure-risk relations established beforehand. Risk-based criteria have been applied to decisions about soil remediation in the form of soil clean-up standards [26], to the use of soils for specific purposes and in the United States also to sediment management [27]. The risk-oriented policies considered here [28], assume that background exposure to pollutants carries no risk and that a specified level of soil pollution carries a maximum tolerable or maximum acceptable risk for organisms living locally. The latter is the main basis for standard setting.

In part, risk-oriented soil pollution legislation includes policy goals that are qualitative [29]. For instance, the primary UK legislation on contaminated soil defines land as contaminated in need of risk management 'if significant harm is being caused or there is a significant possibility of such harm being caused' [29]. Mostly, however policies have resulted in specific quantitative values for maximum tolerable or acceptable soil pollution. The analysis of such values used in different industrialized countries has shown that there are very large differences, roughly up to a factor [30]. According to Provoost et al. [31], these differences to a large extent originate in different political choices (e.g. including or excluding ecotoxicity) and in different assumptions as to the modeling of exposure to soil pollutants, including site related factors, such as soil type and building constructions [31].

\subsubsection{Risks related to one soil pollutant}

In practice, there are several matters which are at variance with the proper establishment of actual risk related to one soil pollutant. These are: the absence of standards for pollutants, neglect of background exposure, and neglect of routes of exposure to soil pollution, neglect of available dose- effect studies and neglect of biological availability. These will now be discussed in more detail.

a. Absence of quality standards 
When data regarding soil pollutants are available, they should be compared with quality standards reflecting maximum tolerable risk of exposure. However, such standards are not always in place. For instance, of the volatile organic carbon compounds detected in groundwater samples by the US Geological Service, were unregulated- with no standards in place [32]. Similarly Patterson et al. [33] found a variety of brominated ethenes in Australian groundwater, all lacking standards.

\section{b. Neglect of background exposure}

For a proper estimate of soil pollution related risks, exposure to specific soil pollutants should be evaluated in combination with exposure to the same substance that is not related to local soil contamination. Several countries, such as Canada, Germany, Spain and Belgium, do indeed establish soil clean-up standards while considering background dietary and inhalatory exposure but others, e.g. Sweden, Norway and the Netherlands, do not [34]. Neglecting background exposure or specific types of background exposure may have implications for risk estimates.

c. Neglect of routes of exposure to soil pollution

In evaluating exposure to soil pollutants, assumptions regarding exposure routes are important. In this respect difference between countries may be noted. Soil clean-up standards for lead of Norway and Sweden differ in part because in Sweden the dominant exposure route is assumed to be by drinking water and in Norway it is thought to be by drinking water and ingestion of soil [34].

Inhalation of household dust and soil particles is not always taken into account in governmental decision making about risks of soil pollution. For instance, in the Netherlands inhalation of soil particles has been neglected as an exposure route, but in e.g. Spain it is not [34]. Neglect of inhalation would seem at variance with existing studies. Nawrot et al. [35] have studied the effects of cadmium pollution in soil (around former thermal zinc plants) and found a significant increase in lung cancer risk correlated with cadmium exposure. They plausibly explain this in terms of exposure of lung tissue to cadmium present in inhaled soil and household dust particles.

Household dust particles have also been found to be important in the exposure of children to pesticides in agricultural settings.

d. Neglect of available dose-effect studies

Akesson et al. [37] have analyzed the effects of low environmental cadmium exposure in an epidemiological study of Swedish women in the Lund area, being 53-64 years of age, excluding women from areas with soils heavily polluted by cadmium. Akesson et al. [37] found associations between the internal dose of cadmium and tubular and glomerular kidney effects, which may represent early signs of adverse effects. Women with diabetes seemed to be at increased risk of experiencing such early signs. In view of these data it seems plausible that at a background exposure that is common in Sweden, old women in the general population may be at risk for adverse cadmium effects [34] and that even a 
modest increase in cadmium exposure due to polluted soil may lead to added risk. However, when establishing soil clean-up standards in Sweden this background exposure has been neglected [34]. Nawrot et al. [35] have studied the relation between mortality and cadmium body burden in Belgium. They obtained evidence that total mortality and noncardiovascular mortality may be elevated at cadmium body burdens which can be found among the population not living on soils that are currently considered to be a health risk. Similarly there are now strong indications that the negative effects of lead on the neurophysiologic and sexual development may well be found at the level of background exposure common in Western European and US cities [37], though soil pollution policy, at least in European counties, assumes that such background exposure is safe [14].

\subsubsection{Ecotoxicological risks}

Maximum acceptable or maximum tolerable ecotoxicological risks are usually derived from a limited number of studies concerning single species under laboratory conditions. Laboratory conditions may be very different from actual conditions in the field, and thus findings in the field are often at variance with laboratory studies [35]. In field studies it has been found that several factors which tend to be neglected in laboratory studies may strongly impact toxic effects of soil pollutants. These include among others: density and adaptability of populations of affected organisms, the presence of other environmental stress factors and the presence or absence of specific landscape elements such as buffer strips [35].

\subsubsection{Biological availability}

Biologically available pollutants determine risk [3]. Biological availability may vary strongly for different types of organisms [36]. Biological availability of a compound in a specific soil is also dependent on physical, chemical and biological and spatial factors [35]. Examples of such factors are $\mathrm{pH}$, the amount and nature of organic and mineral compounds also present and the presence of organisms that can mobilize soil pollutants [37-39]. In practice, biological availability may be much at variance with total concentrations [40].

\subsubsection{Combination effects}

a. Limited accounting of combination effects

As to the overall risk of soil pollutants, cumulative effects of the combination of substances present in soils should be considered. However actual standard setting practice has largely focused on criteria relating to one element or compound. In some cases there are criteria for groups of compounds [34]. Such criteria limit the amount (in $\mathrm{g} / \mathrm{kg}$ soil) of groups of compounds but often do not address the possibility that the risk per unit of weight may be different for different compounds. An exception to this is criteria for the presence of halogenated dioxins and benzofurans and planar biphenyls. The establishment of risk in case of exposure to these compounds uses addition on the basis of equivalent toxicity [40]. This is a major improvement, though it has been pointed out that this approach may still underestimate the risk of neurodevelopment effects [41]. 


\section{b. Importance of combination effects}

Combination effects may be important in two respects. Firstly, coexisting soil contaminants may impact each others' biological availability [43]. Secondly, exposure to a combination of pollutants may be associated with antagonistic, synergistic and additive interactions of these pollutants, impacting their effect on organisms [44-47]. Some risks of pollutant mixtures can be predicted on the basis of existing knowledge. For instance there is a fair chance that there will be dose additivity when effects are receptor mediated [48]. Also in case of narcotic effects, joint-mixture ecotoxicological effects may be predicted [48]. If responses are dissimilar, response addition may be used [49]. A methodology to deal with the ecotoxicity of mixtures giving rise to both dose-additive and response-additive effects has been proposed [48]. This two step model evaluates mixture toxicity for the same mode of action with concentration additivity and the toxicity for different modes of action with response additivity. For determining the severity of ecotoxicological effects in case of heavily polluted soils (in which legal maximum tolerable levels for one or more substances are exceeded), a systematic approach to combination effects based on a mixture of concentration addition and response addition has been proposed [41].

\subsubsection{Remedies for shortcomings}

Remedies would seem possible which would allow for a significant improvement in risk estimates. Unregulated substances can get standards. Standards may be regularly updated on the basis of new dose-effect studies. Risk estimates can include both background exposure and all exposure routes for local soil pollution. Estimates of biological availability can be integrated in risk assessments and improved by better testing of bioavailability or by in-vivo monitoring [51]. The deficiencies in taking account of combination effects in ecotoxicity, discussed in section may be addressed by directly testing of ecotoxicity, when the focus is on ecosystem functioning [52,53]. However it should be noted that small effects on the functioning of ecosystems may have large effects over time [35]. This necessitates large numbers of replicate tests that may well be beyond routine practice [35].

In determining combination effects on human health, direct testing on humans is an 'unethical option'. However biomarker-based monitoring of some aspects of soil pollution relevant to humans may be an option. For instance Roos et al. [54] have applied a biomarker based test to original and remediated soils that were contaminated by a variety of polycyclic aromatic hydrocarbons (PAH). They tested the expression profile of cytochromes P 450 [54]. Xiao et al. [55] have measured genotoxic risk of soil contamination using an in-vitro assay with Salmonella. Though the relation between such biomarker-based data gathered and the in-vivo risks awaits further elucidation, the application of tests based on biomarkers for soil pollution is an interesting option in dealing with combination effects on humans.

Also, estimates of risk may be derived from biomarkers which may be monitored in people exposed to soil pollution. Such biomarkers have emerged from epidemiological studies considering the combined effect of substances. An illustration thereof is the study by Lee et al. [56] which found a graded association of the concentration of blood lead and urinary cadmium 
concentrations with oxidative stress related markers in the US population. This suggests that oxidative stress may be useful as a biomarker for combination effects. It has furthermore been proposed to evaluate effects of exposure to nitroarenes by measuring haemoglobin adducts [57], and of mixtures of volatile organochlorines by measuring glutathione conjugative metabolites [58]. Bioassays based on aryl hydrocarbon (Ah) receptor mediated mechanisms have been proposed which will allow a better alternative to the measurement of polyhalogenated aromatic hydrocarbons [41]. Another option is to estimate risks to human health by taking into account cumulative combination effects in line with established cause-effect relations and research into the effects of actual combinations. It has been shown that risks of compounds with the same targets and the same modes of action may be estimated on the basis of concentration addition, while including toxicity equivalence factors for the compounds involved [59].

This has been shown to apply to receptor-mediated-and reactive mechanisms of toxicity, provided that no chemical reactions occur between the components of the mixture considered [60]. Currently this approach is applied to halogenated dioxins, benzofurans and planar polybiphenyls, though non-linear interactions are not completely absent in this category of compounds [61], and neurodevelopment effects may be underestimated, as pointed out before [41]. Extension of this approach is possible to e.g. polycyclic aromatics, including heterocyclic polycyclic aromatics $[18,62]$ organophosphates that inhibit the enzyme cholinesterase $[44,63]$, compounds that bind to estrogen receptors [64-66], carcinogens [67], a variety of petroleum products [68] and compounds that inhibit the MXR efflux pump [69].

\section{Ecological risk assessment}

Ecological risk assessment (ERA) is a process of collecting, organizing, and analyzing environmental data to estimate the risk or probability of undesired effects on organisms, populations, or ecosystems caused by various stressors associated with human activities. The basic principles of ecological risk assessment are described in numerous papers [70-72]. All varieties of ERA are associated with uncertainties. The value or usefulness of the different ERA methodologies depends on the uncertainty, predictability, utility, and costs. There are typically two major types of ERA. The first is predictive and is often associated with the authorization and handling of hazardous substances such as pesticides or new and existing chemicals in the European Union. This kind of ERA is ideally done before environmental release. The second type of ERA could be described as an impact assessment rather than a risk assessment, as it is the assessment of changes in populations or ecosystems in sites or areas already polluted. The predictive method is based on more or less generic extrapolations from laboratory or controlled and manipulated semi field studies to real-world situations. The descriptive method is more site specific as it tries to monitor ecosystem changes in historically contaminated soils such as old dumpsites or gas facilities or in field plots after amendment with pesticides or sewage sludge, for example.

Often ERA is performed in phases or tiers, which may include predictive as well as descriptive methods. The successive tiers require, as a rule of thumb, more time, effort, and money. The 
paradigm or schemes for ERA may vary considerable from country to country, but often consist of an initial problem formulation based on a preliminary site characterization, and a screening assessment, a characterization of exposure, a characterization of effects, and a risk characterization followed by risk management. Although exposure assessment is often just as or even more important, this chapter primarily considers effect assessment. In most European countries, ERA of contaminated soils consists of rather simplified approaches including soil screening levels (SSL) (a.k.a. quality objectives, quality criteria, benchmarks, guideline values) and simple bioassays for a first screening of risk [73-75]. National research or remediation programs have led to the development of a large variety of guideline values.

Although hard to categorize, most fall into two categories: generic or site specific. While the site-specific guidelines require a characterization of $\mathrm{pH}$, organic matter, etc., at the site, generic guideline values are more independent of modifying factors and hence straightforward to legislate. Three major classes of tools for assessing ecological effects may be identified: standardized ecotoxicity experiments with single species exposed under controlled conditions to single chemicals spiked to soil; ex situ bioassays, here defined as simple laboratory assays where single species are exposed to historically contaminated soils collected in the field; and finally monitoring, analyzing, and mapping of population or community structures in the field. Furthermore, mesocosm, lysometer, or terrestrial model ecosystems (TME) may be useful; these may be considered as large (multispecies) bioassays or ecotoxicity tests [76-79]. TMEs have the advantage that they operate with the (relatively) undisturbed intrinsic soil populations that make up a small food web. TME hence allow the assessment of effects of toxicants that are mediated through changes in food supply or competition and predation.

One of the keystones in deriving environmental quality criteria is the use of standardized terrestrial test procedures. The emphasis of these prognostic tests is on reproducibility, standardization, international acceptance, and site independence. Although increasing in numbers, relatively few terrestrial tests are still approved by the International Standardisation Organisation (ISO) or Organization for Economic Cooperation \& Development (OECD). However, other tests have shown promising results and are likely to be prepared for standardization in the future [80].

However, the major problem in using simple laboratory tests to extrapolate to contaminated land may not be the limitations of test species and the natural variation in species sensitivity. The problems associated with extrapolating from one or a few species, exposed under controlled and typically optimal conditions, to the complex interaction of species and chemicals found in most contaminated ecosystems should also cause concern. Although singlespecies laboratory tests with spiked materials have their obvious benefits, e.g., they measure direct toxicity of chemicals and interpretation is therefore simple, supplementary tools are often needed. Bioassays, as defined in this context are one of the more frequently used highertier alternatives. Basically the same test species may be used in bioassays for assessing the risk of a specific contaminated soil as in standard laboratory tests. However, bioassays have the advantage, compared to the use of spiked soil samples, that the exact toxicity of a specific soil may be accessed directly: this includes the combined and site-specific toxicological effect of the mixture of contaminants and their metabolites. Furthermore, the in situ bioavailability of 
that specific soil is (at least almost) maintained in the laboratory during the exposure period. Several studies have shown a reduction in bioavailability and/or toxicity of soils with an old history of contamination [80-85].

Bioassays are therefore often considered a more realistic tool than generic soil screening levels based on spiked laboratory soils. However, a number of uncertainties or problems may be associated with the use of bioassays and the interpretation of their results. First, the test species are still exposed to the contaminants in a relatively short period compared to the permanent exposure condition found at contaminated sites. Furthermore, they are exposed under more or less optimal conditions, in that stressors such as predation inter- and interspecies competition, drought, frost, and food depletion are eliminated during exposure. Finally, typically only a few species are tested individually.

To compensate for some of the limitations just described, contaminated soil may be assessed using multispecies mesocosms, lysometers, or TME. In these, species interactions may be evaluated by manually introducing several species to the systems or monitoring the intrinsic populations of the soil. Natural climatic conditions may be included if the test system is kept outdoors. However, if we want to get a more realistic and large-scale picture of the impact caused by, for example, pesticide use or sewage sludge application, or to assess the environmental health at waste sites, industrial areas, or gas works, it is often necessary to conduct some kind of field observations. Several case studies exist in which field studies have successfully elucidated the ecological risk of specific activities or the ecological impact at specific sites [85-87]. The small single-species bioassay, large multispecies TME, and field surveys have some drawbacks in common. First of all, it may be difficult to actually link the observed effect to a specific toxic component in the soil. Which of the many substances is actually causing the majority of the observed effects, or is it perhaps a combination of effects? For a hazard classification of soils or a ranking of soils this may not be so important.

However, to evaluate potential risk-reduction measures or risk management procedures it may be important to identify the most problematic substances. A comparison of soil screening values with measured concentrations for each chemical present at a site may be helpful to identify the most likely group of substances causing the observed effect. Other possible tools may include a toxicity identification evaluation (TIE) approach [88]. The TIE approach is a relatively new method, which aims to identify groups of toxicants in soils with mixed pollution. Potentially toxic components present in the soil are fractionated and determined, and the toxicity of each individual fraction is determined by a $\operatorname{Lux}$ bacteria-based bioassay or the Microtox bioassay. Although perhaps promising, TIE is a time-consuming and hence costly procedure not yet used routinely. Another crucial issue when analyzing the result of bioassays, TME, and field studies is the presence or absence of a proper reference site or soil. The control soil should in principle resemble the contaminated soil in all relevant parameters, e.g., texture, $\mathrm{pH}$, organic matter, waterholding capacity, and nutrient content, a practical problem that very often is difficult to solve. The lack of adequate control or reference sites may, however, be conquered at least partially by the use of multivariate techniques [89], which relate the species composition and abundance to gradients of pollutants. It is not the intention of this chapter to 
present a review of statistical tools for ecological risk assessment, and hence a detailed discussion about the use of these is not given.

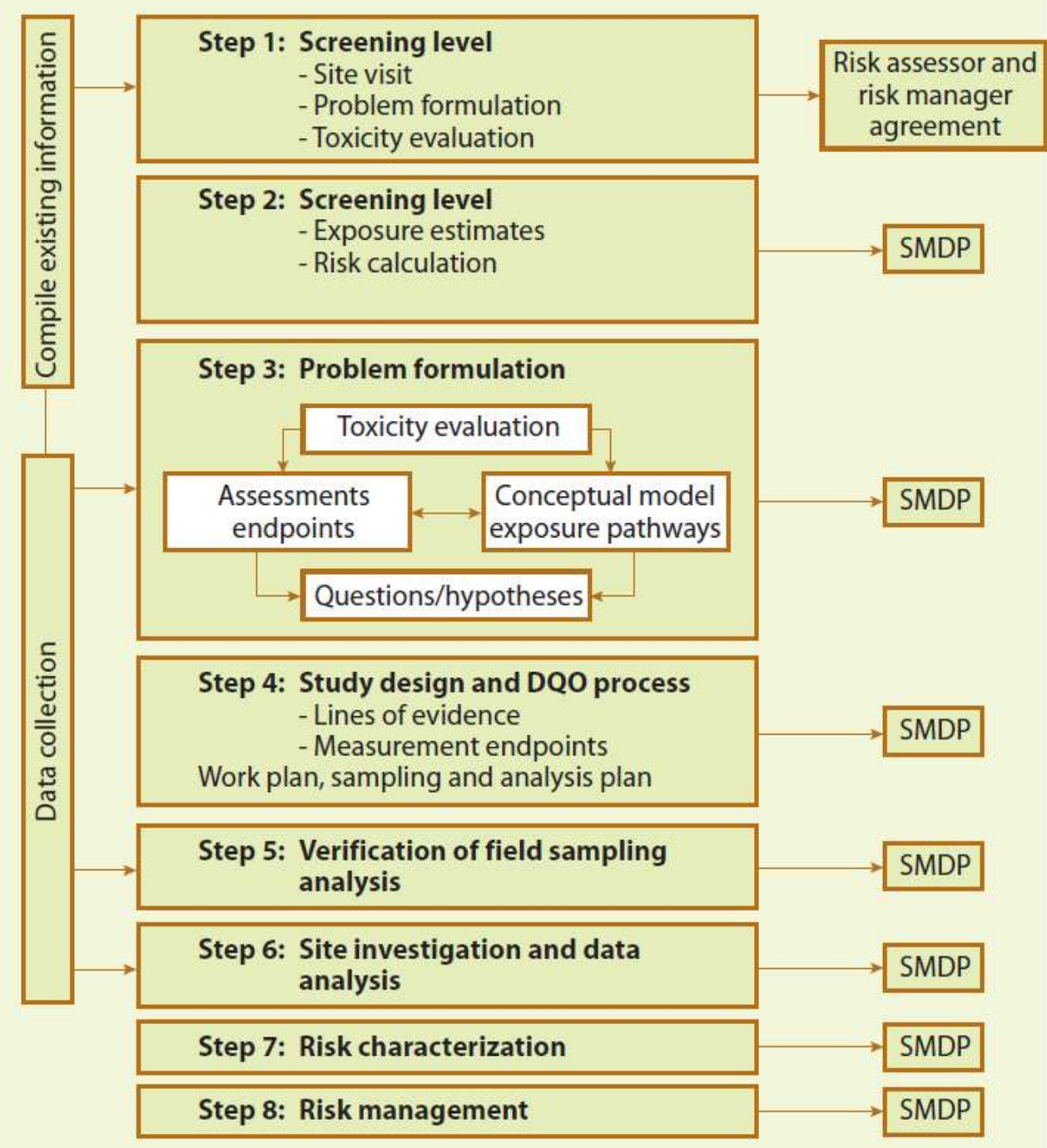

Figure 2. The eight steps in the US-EPA framework for risk assessment of contaminated Superfund sites. DQO = data quality objectives [89]

However, it is obvious that increased computer power and the presence of new easy-to-use software tools have increased the possibility to move away from more conventional univariate statistics such as analysis of variance (ANOVA) to more powerful multivariate statistics that 
use all collected data to evaluate effects at a higher level of organization. Statistical methods such as the power analysis may also be very useful in planning and designing large-scale ecotoxicity studies such as mesocosms,TME, or field surveys.

The US-EPA has published an Ecological Risk Assessment Guidance, which should be followed when assessing risks at Superfund sites. As all sites are considered unique this should always be done in a site-specific manner. The ERA process suggested by the US-EPA for Superfund sites follows an eight step process, which can be broken down into four categories, i.e. 1) planning and scoping, 2) problem formulation, 3) stressor response and exposure analysis and 4) risk characterisation. Essential for all steps are a negotiation and agreement of the need for further action between the risk assessor, the risk manager and other stakeholders, the so-called scientific-management decision points (SMDP).

SMDP made at the end of the screening-level assessment will not set an initial cleanup goal. Instead, hazard quotients, derived in this step, are used to help determine potential risk. Thus, requiring a cleanup based solely on those values would not be very likely, although it is technically feasible. There are three possible decisions at the SMDP:

1. There is enough information to conclude that ecological risks are very low or non-existent, and therefore there is no need to clean up the site on the basis of ecological risk.

2. The information is not adequate to make a decision at this point, and the ecological risk assessment process will proceed.

3. The information indicates a potential for adverse ecological effects, and a more thorough study is necessary.

In the Netherlands contaminated sites are first determined using a set of soil screening levels called target and intervention values, which take both human and ecological risks into account. At seriously contaminated sites remediation or other soil management decisions are required if the risks cannot be neglected based on a site-specific ecological and human risk assessment, and the chance for dispersion of the contaminants. Until now, the ecological risk assessment has been based on chemical analysis, including a Decision Table harbouring critical dimensions of the impacted area. The United Kingdom and Canada have also developed framework for ecological risk assessment of contamination land. A cornerstone in the UK framework of ERA is the connection to the statutory regime for identification and control of land potentially affected by contamination. The UK framework is based on schemes found in e.g. USA, Canada and the Netherlands. Like these it is a based on a tiered approach where the initial Tier 0 aims to determine whether a site falls under the Part IIA of the legislation. It involves the development of a Conceptual Site Model (CSM), which described what is already (historically) known about the site, e.g. whether there is a likely source-pathway-receptor linkage. The conceptual site model is followed by an initial screening phase (Tier 1) and an actual site-specific characterisation (Tier 2). Tier 1 is a simple deterministic comparison of chemical residue data and the soil quality guideline values supplemented with simple soil-specific toxicity testing. The final step (Tier 3) involves more detailed in-situ studies and for example ecological modelling based on a more advanced ecological theory. Tier 3 is not likely to be conducted at many sites. 


\subsection{Descision support system for ecological risk assessment}

Ecological Risk Assessment is often a complex process with many variables to take into account. ERA involves many stakeholders and all have to be dealt with in a clear and consistent way. A stepwise or tiered approach is therefore useful to overcome the complexity of an ERA. In order to structure all the information collected, a Decision Support System (DSS) can be used. Each tier will lead to a decision to proceed or to stop. A number of decisions supporting systems or frameworks have already been developed in other countries, e.g. UK, the Netherlands and the USA. The DSS presented here is based on basic principles also common in the methodologies used in the USA and UK. However, in the present DSS measures of bioavailability and the use of the Triad approach may be built into the system more systematically. This chapter introduces the overall framework of a novel DSS including the Triad approach and the challenge to weight and scale results used in that process.

\subsection{Framework for ecological risk assessment}

Rutgers et al. (2000) developed a basic flowchart for Ecological Risk Assessment [90], which is used as the backbone of the decision support system (DSS) presented in the Figure 5.

The DSS is separated in three different stages, i.e.

- Stage I. Site characterization and description of land-use.

- Stage II. Determination of ecological aspects.

- Stage III. Site-specific tiered assessment (the Triad):

- Tier 1. Simple screening

- Tier 2. Refined screening

- Tier 3. Detailed assessment

- Tier 4. Final assessment.

Each of these four tiers is based on a weight of evidence (WoE) approach combining three lines of evidence (Chemistry, (eco)Toxicology and Ecology).

\subsubsection{Boundaries of the DSS}

The DSS in this chapter is not a full and comprehensive document for managing risk of contaminated land. It focuses strongly on supporting decisions made when considering risk to the terrestrial environment. Therefore it addresses only indirectly the risk to ground water and associated (connected) fresh water systems. Nevertheless information about e.g. reduced bioavailability may be useful when assessing potential risk for leaching of contaminants to ground water or fresh water. Furthermore, it is important to realise that the management of a contaminated site is more than assessing ecological risk. Issues like for example risk for humans, availability and cost of remediation solutions, development plans for the vicinity or the region are equally important. 


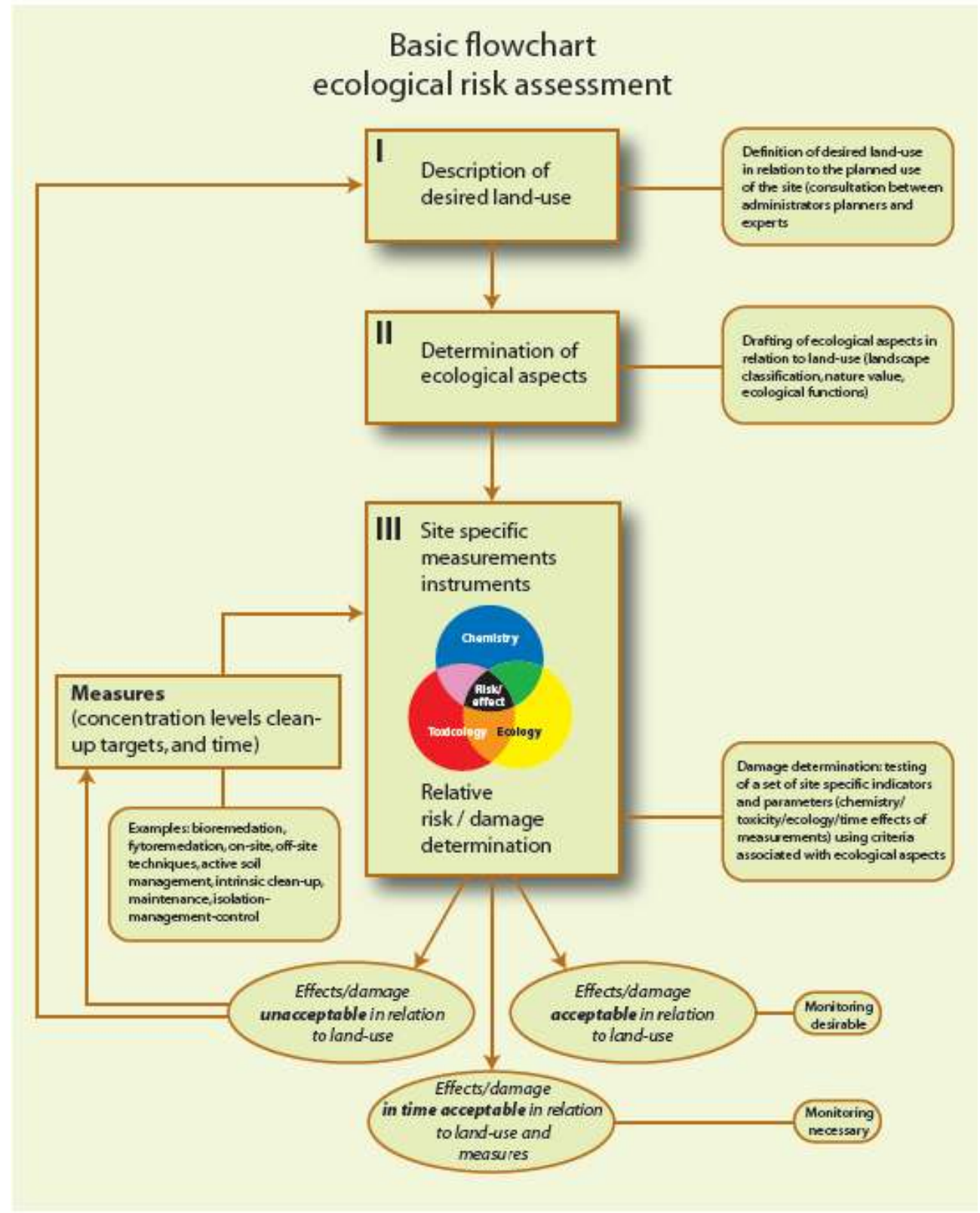

Figure 3. Basic flowchart for ecological risk assessment [90] 


\subsubsection{Stage I - Site characterisation and land-use definition}

The first step in the DSS is to establish what is often referred to as a Conceptual Site Model. It aims at involving as many stakeholders as possible in order to describe site characteristics and to review all available information from the site, e.g. historical information about land-use, investigation of whether the site may be regulated under specific directives, obvious data gaps and urgency for reaction and data collection. The spatial borders of the site should be defined and the current and the future landuse have to be defined. Consultation between administrators, planners and experts therefore has to take place as early as possible in the process.

a. Initial requirements in the DSS

An inquiry among all stakeholders should be conducted as one of the first initiatives. The aim should be to collect as much information about soil characteristics as possible.

b. Defining land-use

One of the first actions to be taken among all stakeholders is to decide which landuse is required for the site, as this will determine the required data collection and testing. Many land-uses may be defined, but generally the four following overall categories of land-use classes are used:

- industrial area (including infrastructure and pavement).

- urban/residential area (including recreational and green areas).

- agricultural area.

- nature area.

c. When is an ecological risk assessment needed?

Most often a site specific ERA will be initiated only when soil concentrations exceed soil screening levels. However, this may not in itself be a sufficient criterion to go through the entire ERA procedure. Some boundary conditions, based on the present and future type of land-use, the level of contamination and various ecological considerations have to be met in order to rationalize an ERA. The experts and the rest of the stakeholders should answer a number of simple questions in order to conclude whether the required boundary conditions are fulfilled.

\subsubsection{Stage II - Determination of ecological aspects}

At stage II, site-specific ecological features and receptors relating to the land-use defined in Stage I need to be outlined. This includes aspects like key species and life support functions. The potential ecological receptors should be identified in order to determine whether potential source-pathway-receptor linkages can be established. This includes not only ecological receptors directly linked to the site but also those linked indirectly e.g. through leaching of contaminants to connected fresh water systems or (migrating) birds or mammals feeding in the area. In Table 9 some examples are given of land-use and related ecological aspects. This table can be used as a starting point for the selection of ecological aspect. Experts from ecotoxicology and ecology should be involved in the selection of ecological aspects. 


\subsubsection{Stage III - Site specific instruments (the Triad)}

If after finalising Stage I and Stage II it is still considered that there is a need for a site specific evaluation of ecological risk the process continues to Stage III using the weight of evidence approach described below.

\subsubsection{Weight of evidence approaches}

In order to deal with conceptual uncertainties in a pragmatic way, it has been proposed to use weight of evidence (WoE) approaches for ERA [90-93]. The rationale is, like in justice, that many independent ways to arrive at one conclusion will provide a stronger evidence for ecological effects, making ERA less uncertain.

In the sediment research area the application of WoE started at an early stage and was called the Sediment Quality Triad. For terrestrial ecosystems WoE approaches and the Triad are still in a developing stage. The Triad approach is based on the simultaneous and integrated deployment of site-specific chemical, toxicological and ecological information in the risk assessment as given in Figure 6. The major assumption is that WoE in three independent disciplines will lead to a more precise answer than an approach, which is solely based on, for example, the concentrations of pollutants at the site. A multidisciplinary approach will help to minimise the number of false positive and false negative conclusions in ERA. It also gives acknowledgement to the fact that ecosystems are too complex to analyse in one-factorial approaches.

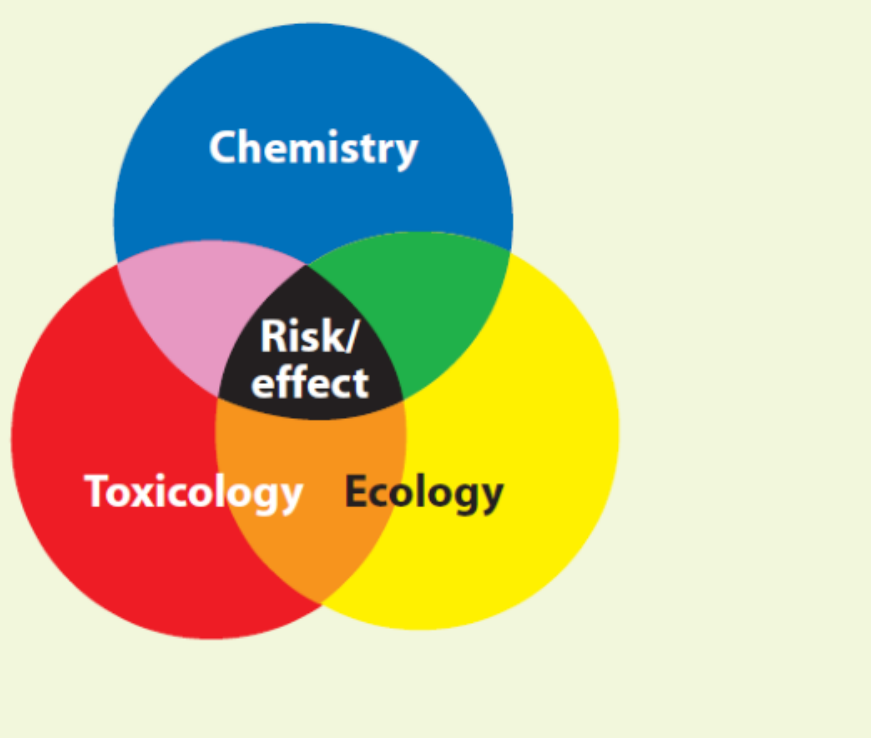

Figure 4. Schematic presentation of the integration of three fields of research according to a Triad [92] 
- Chemistry: The concentration of contaminants in the environment (totals, bioavailable), accumulated in biota, or modelled via food-chains is used for calculation of risks on the basis of toxicity data from the literature.

- Toxicology: Bioassays with species across genera are carried out in order to measure the actual toxicity present in environmental samples from the site.

- Ecology: Field ecological observations at the contaminated site are compared to the reference site. Deviations from the reference site, which can be plausibly attributed to the contamination levels, are funnelled into the Triad.

\subsection{Using the TRIAD in site specific assessment of contaminated soil}

Triad is a powerful weight of evidence approach originally developed in order to evaluate sediment quality. In the terrestrial compartment less experience is available on the practical use of the Triad. This chapter describes the use of Triad in more detail and gives an insight into some of the important decisions risk assessors have to make when conducting the Triad in practise, e.g. how to scale, weight and integrate the outcome of the various investigations.

The Triad approach exists of three lines of evidence (LoE), the so-called Triad "legs", i.e. chemistry, (eco) toxicology and ecology. The Triad approach includes a tiered system in which each consecutive tier is increasingly fine-tuned to the site-specific situation. In the first tier the research is simple, broad and generic. In later tiers more specific and complex tests and analyses may be used. For each of the LoE in the Triad there are a variety of analyses or tests that can be chosen. Some examples are:

- Chemistry: Measurement of total concentrations, bioavailable concentrations, bioaccumulation, etc.

- Toxicology: Bioassays (in field and/or in lab), biomarkers etc.

- Ecology: Field observations of vegetation, soil fauna, micro-organisms, etc. In Chapter 6, a number of tests or tools that are for suitable for use in each tier are presented for the chemistry, toxicology and ecology LoE.

\subsection{Decision charts in ecological risk assessment of contaminated sites}

\subsubsection{Flowcharts}

This chapter is an attempt to present a decision support system, which can guide risk assessors in their assessment of site-specific ecological risk. A number of site-specific questions need to be answered before a final decision on performing an ecological risk assessment can be made. This chapter introduces a flow chart for ecological risk assessment of contaminated sites. The flowchart is presented as decision trees as shown in Figure 8 together with a more in-depth introduction to the relevant questions that needs to be addressed and answered when performing a site-specific ecological risk assessment. 


\subsubsection{Decision making in ERA}

The assessment of ecological risk is performed stepwise in tiers. Higher tiers represent gradually more and more complex studies, but also more expensive and laborious studies. The full site-specific risk assessment covers four tiers, i.e.

- Simple screening: Tier 1.

- Refined screening: Tier 2.

- Detailed assessment: Tier 3.

- Final assessment: Tier 4.

The main principle in going from a simple screening over a more refined screening to a detailed assessment of the contaminated site is to minimize time and effort. The actual performance of the risk assessment and use of the various tiers may be very site-specific.

a. Tier 1 - Simple screening

After deciding in the two first stages of the ERA that ecological concern needs special consideration, the risk assessment starts typically with a simple evaluation at the screening level. This is done in order to minimize costs until new information indicates the need for further assessment and more sophisticated studies. Therefore, the tools used in the first screening need not only to be reasonably quick and easy, but also relatively cheap. The tools for use in Tier I are described in more detail in the toolboxes C1, T1 and E1. On the basis of the results of instruments used in Tier 1 it is decided to either stop further assessment or continue to a higher tier.

b. $\quad$ Tier 2 - Refined screening

Tier 2, still considered being at the screening level, aims at refining the measurement of exposure and at the same time to provide further insight into the toxicological and ecological properties of the contaminated soil. Tier 2 deviate from the conservatism normally associated with the use of total concentration in the risk assessment by taking (rough) estimations of bioavailability into consideration in the chemical LoE. A better screening of the toxicological and ecological properties of the soil compensates for the reduced conservatism in the Chemistry LoE of the Triad. The tools for use in Tier 2 are described in more details in the toolboxes C2, T2 and E2. On the basis of the results in Tier 2 a decision should be made to either stop further assessment or continue to a higher Tier.

c. Tier 3 - Detailed assessment

The tools in Tier 3 differ from the ones used in Tier 1 and Tier 2 in that they are more laborious, costly and may take longer. On the other hand they are (often) more realistic and/or ecological relevant in order to give a more comprehensive assessment of the ecological risk at the specific site. The stakeholders should beforehand negotiate a minimum set of tests. Is it for example necessary to consider all trophic levels in the toxicological and ecological LoE? Or does the land-use suggest otherwise? Is it necessary (or possible) to estimate the bioavailability of all the substances exceeding their SSL? If not, how are the non-investigated substances dealt with? 
The tools described for use in Tier 3 are described in more details in the toolboxes C3, T3 and E3. Depending on the results from Tier 3 a decision should be made to either stop further assessment or continue with an even more detailed assessment in Tier 4

d. Tier $4-$ Final assessment

In Tier 4, the aim of the studies is to answer any remaining questions and to decrease existing uncertainties and this may often require more in-depth research. Tools in Tier 4 can be similar to tools of Tier 3, but more focus has to be on site-specific circumstances. For example bioassays should be done with organisms, which normally occur at the site. Furthermore, it may be more relevant to consider ecological effects outside the contaminated area on e.g. predators or herbivores feeding in the area or effects in adjacent fresh water systems. This Tier requires specialised knowledge and experience with ERA, which implies that costs can be high and only a limited number of people may be able to perform the tests. Generally only on a very limited number of site evaluations will include investigations at this level. If the results of Tier 4 still indicate risk there are basically two possible solutions. Accept the risk and leave the contamination or remove (parts of) the contamination.

\subsubsection{Screening tools}

\subsubsection{Triad based selection of methods}

For each of the three Lines of Evidence (LoE) in the Triad various methods or tools are available. In order to facilitate the selection of appropriate tools in the right context, the tools have been compiled in subclasses or toolboxes. Each of these is a collection of tools considered to be potentially useful in the designated tiers and LoE of the Triad, i.e. chemistry, toxicology and ecology. Furthermore, the tools are arranged according to their complexity, price and practicability or in other words depending on whether they are most useful for screening or detailed assessment, i.e.

- Toolbox C1. Chemistry tools for simple screening.

- Toolbox T1. Toxicology tools for simple screening.

- Toolbox E1. Ecology tools for simple screening.

- Toolbox C2. Chemistry tools for refined screening.

- Toolbox T2. Toxicology tools for refined screening.

- Toolbox E2. Ecology tools for refined screening.

- Toolbox C3. Chemistry tools for detailed assessment.

- Toolbox T3. Toxicology tools for detailed assessment.

- Toolbox E3. Ecology tools for detailed assessment.

- Toolbox IV. Various tools for the final (Tier 4) assessments.

a. Toolbox $\mathrm{C} 1$ - Chemistry tools for simple screening 
At the very first stage of the ERA process, total concentrations of all relevant chemicals are individually compared to soil screening levels (SSL) in order to evaluate whether there is a need for a site specific assessment of ecological risk. In the current Stage III of the ERA, this first generic evaluation of risk is followed by a more site-specific screening of risk including information from all three lines of evidence in the Triad. In the Chemistry part of the Triad more site-specific information is collected by:

Refining and targeting the comparison of soil concentrations with soil related benchmarks for site-specific purposes.

Incorporation of the accumulative risk of a mixture of contaminants by calculating the toxic pressure (TP) of a mixture and by doing so generating more site-specific insight to the potential ecological impact of a contaminated site. Each of these steps can be done separately or in combination, e.g. the TP can be calculated using existing SSL or using new developed benchmarks based on either NOEC or EC50 values or site-specific benchmarks can be compared to soil concentrations individually. The approach entirely depends on the strategy taken by the stakeholder group and the availability of data.

b. Toolbox T1 - Toxicology tools for simple screening

The main objective of the selected toxicity tests or bioassay at Tier 1 should be to screen the soil for presence of toxic compounds. This includes toxic degradation products or compounds, which are not routinely included in various national analytical programs for contaminated sites. This Tier is the first screening level of the ERA and the cost in form of manpower and money should hence be relatively low.

c. Toolbox E1 - Ecology tools for simple screening

Ecological surveys or monitoring studies are generally considered a time consuming effort performed by experts. This is in most cases true, wherefore detailed surveys normally take place in higher tier assessment. However, in order to ensure that also ecological information is collected and used in the Triad already in the screening phase, it is recommended to perform a limited examination of the site. A survey of the area with special focus on visible changes in e.g. plant cover or presence or absence of specific plants, trees or scrubs may indicate ecological damage, which can be associated to contaminants present at the site.

If any aerial pictures areavailable from the area these may give valuable information about the plant cover also historically, which may be helpful in identifying parts of the site where the impact may be highest (hot spots). At this stage the conclusion can in most cases only be indicative. Therefore if the results from the other line of evidence may cause any doubt or the survey indicated potential impact, it is recommended to either continue with a more refined screening in Tier 2 or go directly to the detailed assessment in Tier 3.

d. Toolbox C2 - Chemistry tools for refined screening

Selective solvent extraction

It may be considered useful to adjust the estimate of exposure by taking bioavailability into consideration and hereby deviating from the conservatism normally associated to the use of 


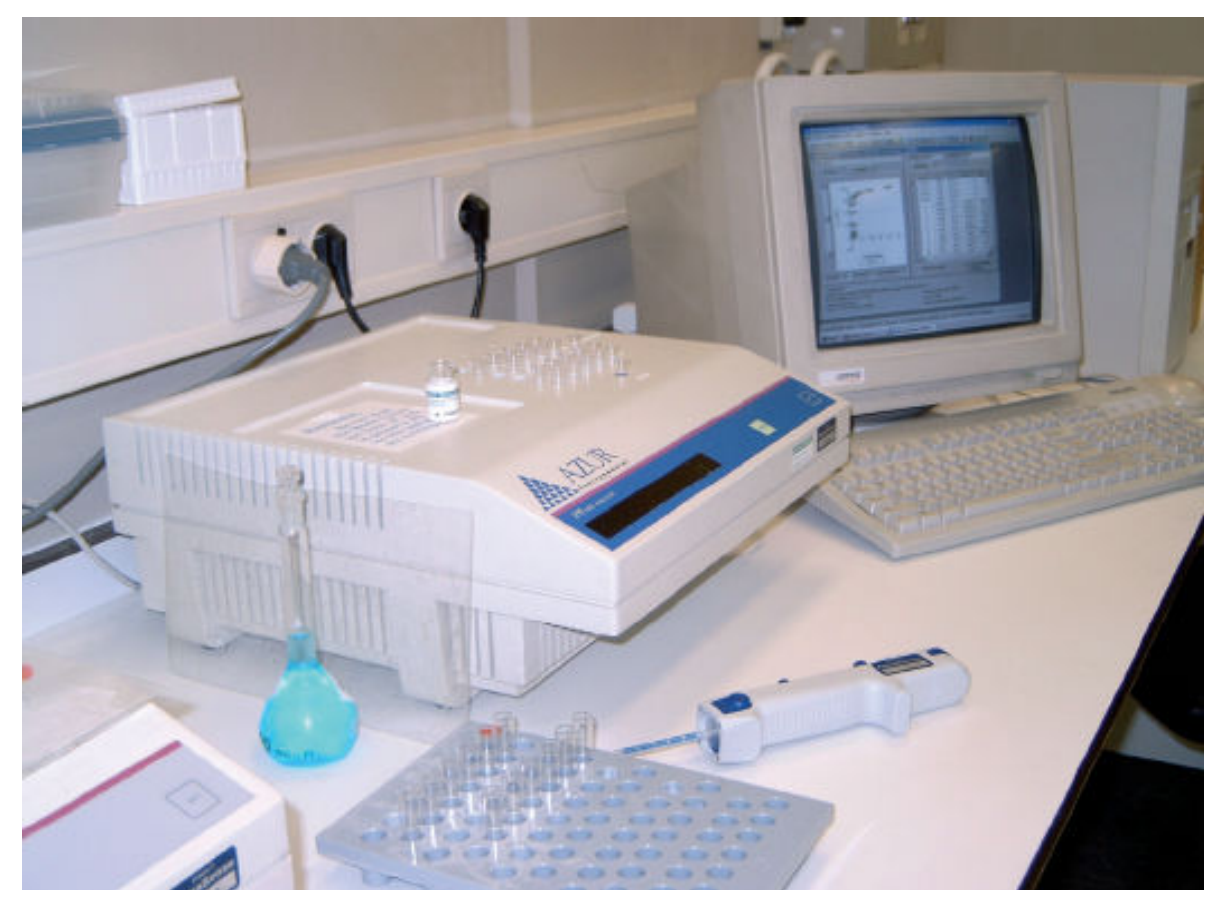

Figure 5. Equipment for measuring luminescence of Vibrio fischeri [94]

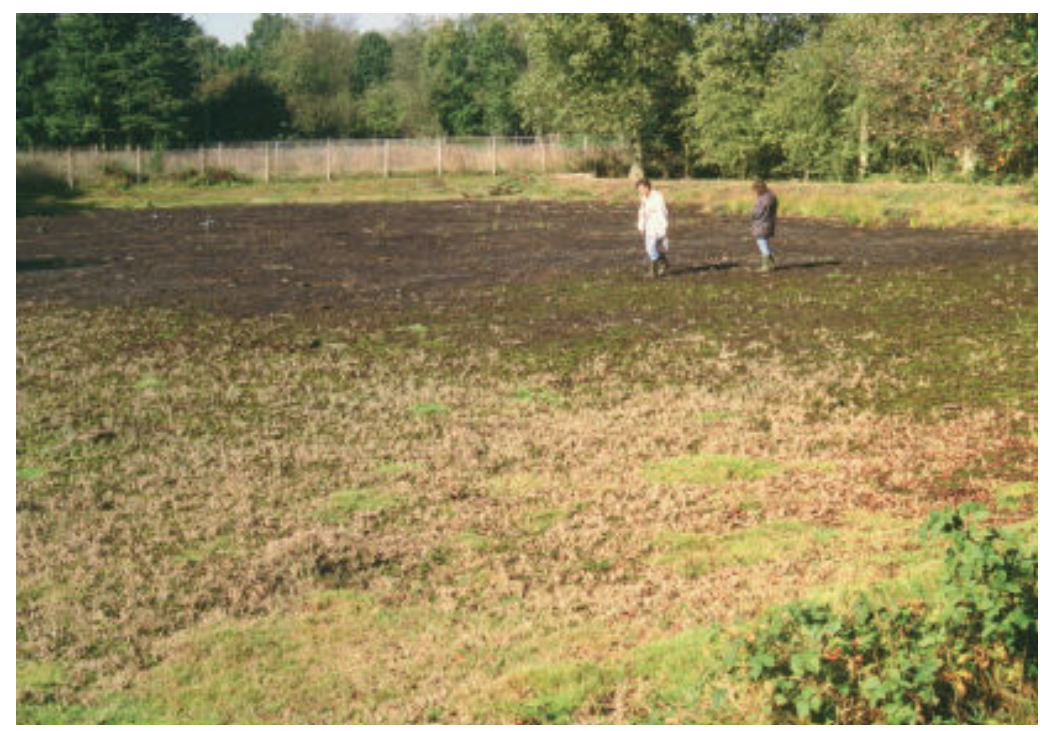

Figure 6. Simple survey of the site [95] 
total concentration in the risk assessment. The principle in this refinement of the ecological risk assessment is to extract a more ecotoxicologically relevant fraction of the contamination than the total concentration. The latter generally tends to overestimate the risk of historically contaminated soils. In this screening phase no attempt is made to estimate the freely dissolved or readily bioavailable concentration of contaminants. Table 10 explains principal studies that employed chemical extractants to evaluate bioavailability.

\begin{tabular}{|c|c|c|c|c|}
\hline Contaminant (Ref) & Solvent & Bioassay & Operation & Comments \\
\hline $\begin{array}{l}\text { Atrazine } \\
\text { Phenanthrene (1) }\end{array}$ & $\begin{array}{l}\text { Methanol/water, } \\
\text { n-Butanol }\end{array}$ & $\begin{array}{l}\text { Earthworm } \\
\text { uptake } \\
\text { Degradation }\end{array}$ & $\begin{array}{l}25 \mathrm{ml} \text { extractant, } \\
10 \mathrm{~g} \text { solid. } \\
\text { Shaking for } 2 \mathrm{~h}\end{array}$ & $\begin{array}{l}\text { Methanol/water } \\
\text { best predictor for } \\
\text { atrazine, n-butanol } \\
\text { for phenanthrene. }\end{array}$ \\
\hline $\begin{array}{l}\text { DDT, DDE, DDD } \\
\text { PAH (mixture) (2) }\end{array}$ & $\begin{array}{l}\text { THF } \\
\text { Ethanol }\end{array}$ & $\begin{array}{l}\text { Earthworm } \\
\text { uptake }\end{array}$ & $\begin{array}{l}15-20 \mathrm{ml} \\
\text { extractant, } \\
1 \mathrm{~g} \text { soil, } \\
10 \text { sec mixing }\end{array}$ & $\begin{array}{l}\text { Good correlation } \\
\text { with earthworm } \\
\text { accumulation. }\end{array}$ \\
\hline $\begin{array}{l}\text { Anthracene, } \\
\text { Fluoranthene, } \\
\text { Pyrene (3) }\end{array}$ & $\begin{array}{l}\text { n-Butanol } \\
\text { Propanol } \\
\text { Ethyl acetate }\end{array}$ & $\begin{array}{l}\text { Plant retention } \\
\text { Earthworm uptake } \\
\text { Degradation }\end{array}$ & $\begin{array}{l}25 \mathrm{ml} \text { extractant, } \\
1-2 \mathrm{~g} \text { soil, } \\
5 \text { sec mixing }\end{array}$ & $\begin{array}{l}\text { Reasonable } \\
\text { correlation } \\
\text { with bioassays. }\end{array}$ \\
\hline $\begin{array}{l}\text { Phenanthrene } \\
\text { Pyrene } \\
\text { Chrysene (4) }\end{array}$ & n-Butanol & $\begin{array}{l}\text { Earthworm } \\
\text { uptake } \\
\text { Degradation }\end{array}$ & $\begin{array}{l}15 \mathrm{ml} \text { extractant, } \\
5-10 \mathrm{~g} \text { soil, } \\
\text { Mixing: } 5 \mathrm{sec} \\
\text { (worm) or } 120 \mathrm{sec} \\
\text { (degradation) }\end{array}$ & $\begin{array}{l}\text { Applicable for } \\
\text { bioavailability } \\
\text { prediction. }\end{array}$ \\
\hline
\end{tabular}

Table 5. Outline of principal studies that employed chemical extractants to evaluate bioavailability

Instead the fraction of the contaminants is extracted, which can be directly compared to the existing soil screening levels. This is considered to be a relatively simple and quick method to screen for potential risk of contaminants in a more realistic way than using total concentrations. The extracted concentration (mg kg-1) is compared to the SSL and the result used in the Triad. It is therefore a prerequisite of this comparison that the extractability in the tests (with spiked soils) used for deriving SSL is close to $100 \%$ by the methods used. In most short-term tests (< four weeks) it will be reasonable to assume that only little "true" ageing or strong sequestering occurs and hence a majority of the spiked chemicals are still extractable with mild organic solvents. However, for most methods this still has to be fully validated.

Organic solvents most frequently used include methanol/water in different ratios, nbutanol, ethanol, propanpol, ethyl acetate and tetrahydrofuran (THF) given in Table 10. The method establishes preferential partitioning of hydrophobic contaminants to the extractant by increasing their solubility in the aqueous phase whilst removing pollutant compounds from soil surfaces establishing equilibrium conditions. No standard protocol has been adopted for mild chemical extractions in relation to bioavailability testing. Common methodology in literature primarily includes a soil sample to which a volume of chemical extractant is added (generally $1-10 \mathrm{~g}$ soil,15 - $25 \mathrm{ml}$ extractant). This is followed by a period for mixing, e.g. vigorous mixing for10 - 120 seconds or shaking by orbital shakers for up to 2 hours. The extraction studies have mostly involved PAH and insecticides (including DDT, DDE, DDD 
and atrazine) [93-95]. Studies that haverelated extractability with results from bioassays have generally focused on uptake and accumulation (\% taken up by earthworms or plants) and bacterial degradation (\%removed). Therefore, since convincing relationships between the chemical and biological tests were found it may indicate a potential for such extraction methods to predict bioavailability.

e. Toolbox T2 - Toxicology tools for refined screening

In the first simple screening of Tier I focus was on marine bacteria and aquatic/sediment living species. In Tier 2 relatively simple tests with soil dwelling species are used for a more refined screening of the soil samples, i.e. the earthworm survival tests and avoidance tests using soil invertebrates.

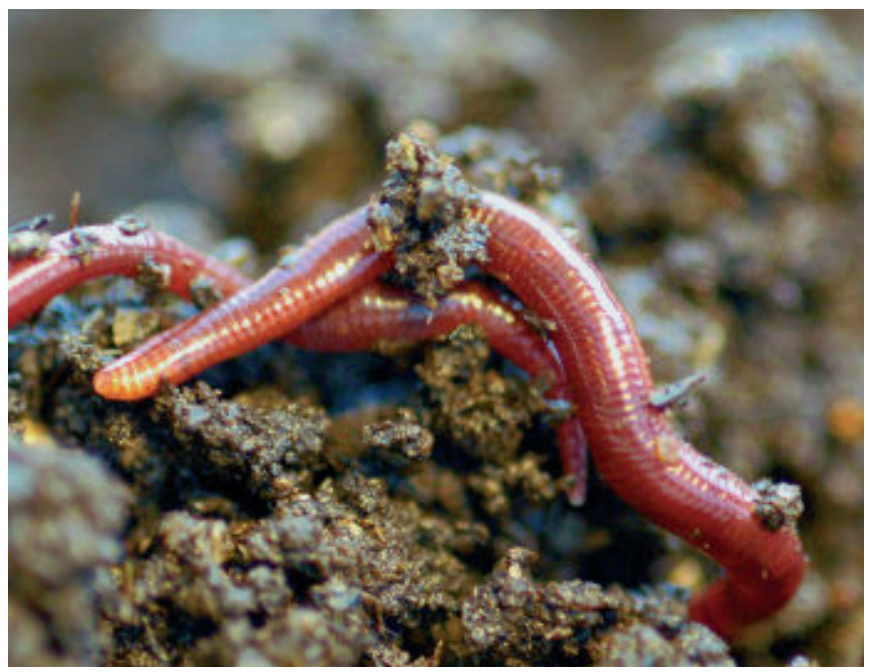

Figure 7. Organisms screening in soil [98]

The habitat function of soils is often assessed using the reproduction test with Eisenia fetida. The avoidance test with Eisenia fetida is a suitable screening test, which is less cost-intensive in terms of duration and workload than the reproduction test, and at the same time (normally) more sensitive than the acute test with the same species.

f. Toolbox E2 - Ecology tools for refined screening

In Tier 2 the observations from the survey may be expanded by simple on-site assessment of the overall soil functioning or biological activity of the soils. Recommended tools include baitlamina sticks and simple microbial tests using general endpoints like soil respiration or $\mathrm{C} / \mathrm{N}$ mineralization rates. 


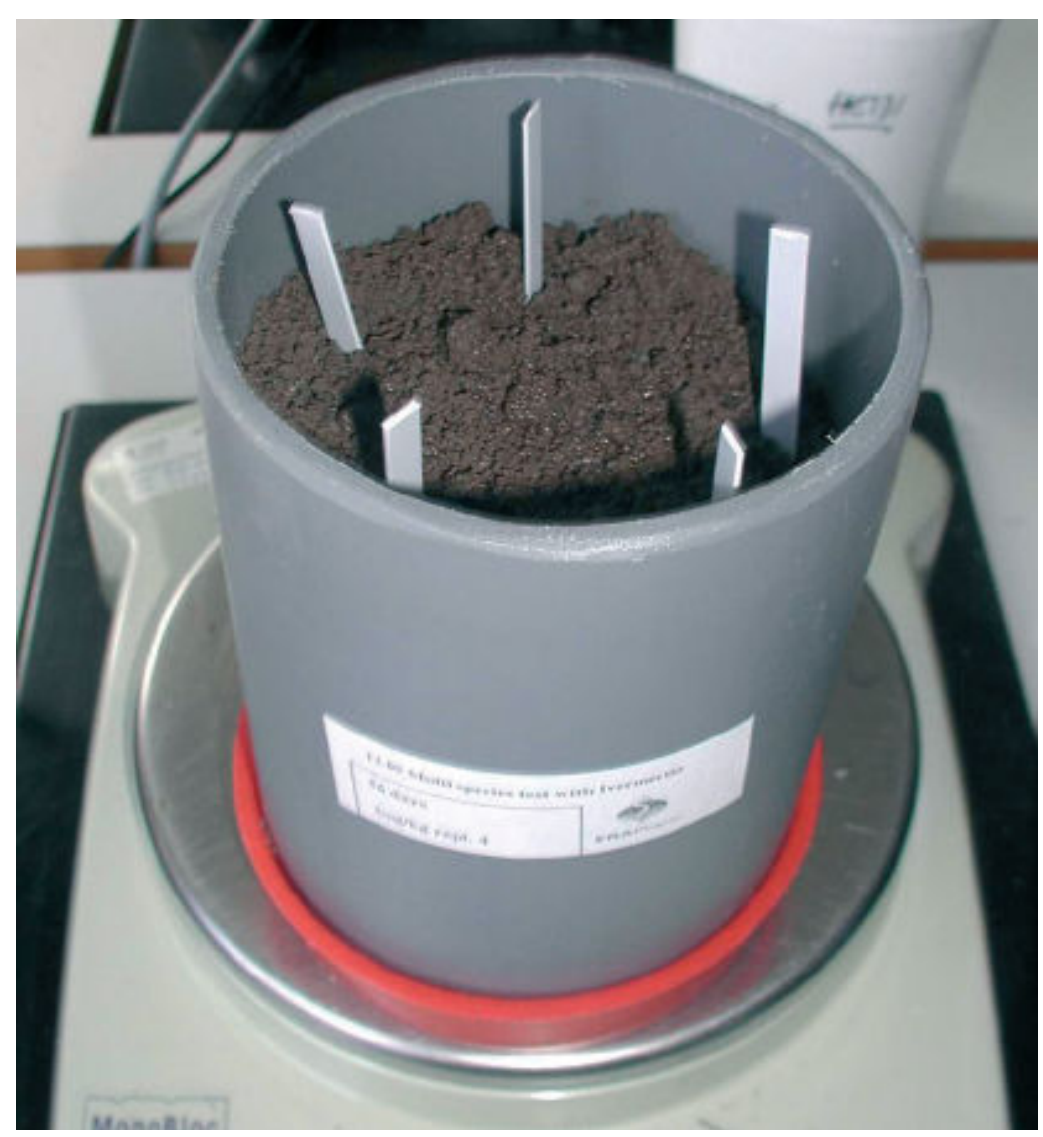

Figure 8. Bait-lamina sticks [99]

The main principle for tests at this level is to be relatively simple and cheap but at the same time to give valuable information whether or not the soil has lost some of its main services. Bait-lamina sticks for example have been demonstrated useful for describing biological activity of the soils in a general matter.

\section{g. Toolbox C3 - Chemistry tools for detailed assessment}

The objective of the tools found in this toolbox is to assess the bioavailable and freely dissolved fraction of pollutants found in pore water of soils from contaminated sites. The methods should (in principle) be able to mimic the fraction of organic pollutants available for uptake in biota. The collection of methods includes various non-depleting and depleting pore water extractions. Very few terrestrial ecotoxicity data are yet expressed as e.g. pore water concentrations. Instead, the outcome of the methodologies in this toolbox is compared with water quality standards. 


\section{h. Toolbox T3 - Toxicology tools for detailed assessment}

The objective of the tools found in this toolbox is to evaluate the potential impact of contaminated soils to fauna and plants and hereby the entire ecosystems. Some of the methods use introduced, and not intrinsic, species. The benefit of this is a higher degree of standardisation, as the species used in these bioassays is easy to maintain in laboratory cultures compared to naturally occurring species. The drawback may be that their ecological relevance is less obvious. For example the compost worm Eisenia fetida is used as a surrogate to evaluate risk to soil dwelling earthworms. Two sets of bioassays are presented. One for directly assessing potential risk for soil dwelling species, including micro-organisms, plants and soil invertebrates, and one for assessing indirectly risk to aquatic species through e.g. leaching of contaminants. It is often anticipated that soil organisms are exposed to pollutants mainly through uptake from pore water. Therefore it may also be possible to evaluate, or at least to compare or rank, the risk of contaminated soil samples to soil dwelling organisms on the basis of the outcome of the aquatic test using elutriate or pore water. The choice of bioassays depends on a number of variables, e.g.:

- The current and future land-use, i.e. targets of protection.

- The size of the contaminated area.

- The potential for ground water or surface water contamination.

- The need of many simple tests or fewer more complicated tests.

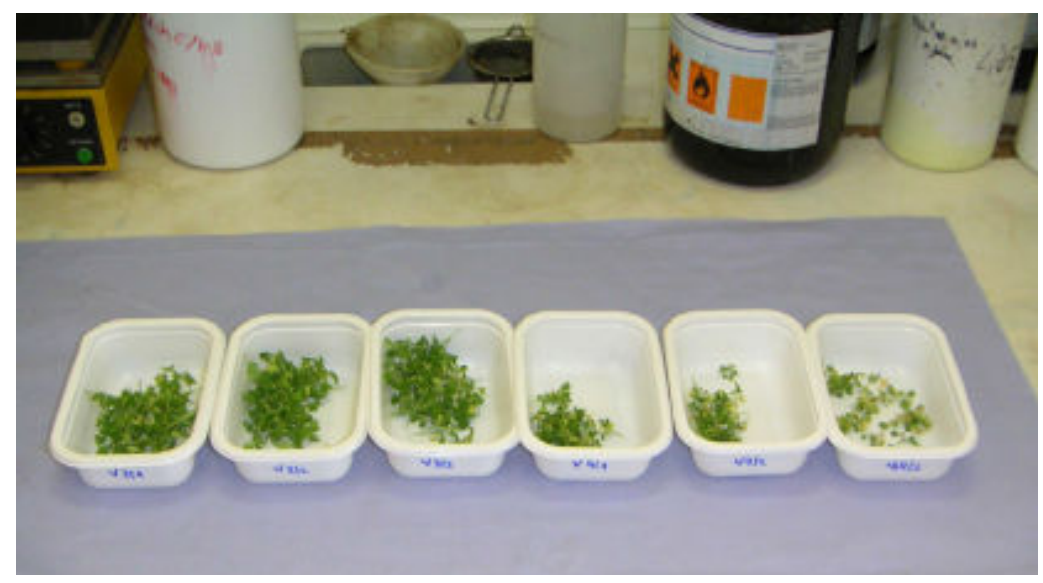

Figure 9. Simple plant tests [91]

\section{i. Toolbox E3 - Ecology tools for detailed assessment}

In this late tier of the Triad, the objective of the activities is community or population response analysis, typically by conducting field surveys. As these studies (most often) are time consuming, costly and dependent on ecologically, taxonomically and statistical expertise they are 
most frequently done on large-scale sites with a long-term- remediation perspective. In fresh water ecosystem community surveys have been widely used with relative success. The absence of species from places where they would be expected to occur could be a strong identification of unacceptable levels of contaminants. However, this type of studies has only seldom been used for the terrestrial environment. The reasons for this are many. One of the dominants may be the lack of a concentration gradient and obvious "upstream" reference sites at most contaminated areas. No world-wide accepted guideline on how to plan and perform a terrestrial field survey is available and hence no straight-forward and easy-to-follow description can be given. The decision on when, where and how to conduct field surveys depends on a number of issues, e.g. the size of the area, the land-use, the type of contaminants present, time of the year and last but not least the time and money available to perform the study. Nevertheless, a number of general considerations have to be made in the planning phase of a successful field survey. These include (but are not limited to):

- Identify the targets of concern and the species to monitor.

- Elucidate the natural temporal and spatial variation before initiating a field study.

- Use statistical (power) analyses to determine the minimum number of samples or replicates needed to emonstrate the decided difference, e.g. $25 \%$ change.

- In order to establish a cause-effect relationship, a number of confounding parameters need to be characterized both at the reference and the test site, e.g. soil type, $\mathrm{pH}$, salinity, hydrology, nutrient- and organic matter content and the presence of other contaminants.

As no single description on how to perform ecological surveys for contaminated sites can be given, some general considerations and useful references for this tier of the ecological risk assessment are given below for:

- Assessing impact in the overall biological activity and organic matter breakdown.

- Assessing impact on the microbial community.

- Assessing impact on the plant community.

- Assessing impact on the invertebrate community.

Reference data from reference sites, reference samples and literature

A crucial factor in a risk assessment is the quality of reference data, because the results of the site-specific ecological measurements or calculations are compared against these data. This is true for as well chemical information (i.e. background levels in that region), toxicological data from bioassays (i.e. site relevant reference soil and well characterized control soil in order to verify the test performance) and ecological field surveys.

The reference soil should in principle resemble the contaminated soil in all relevant parameters, e.g. texture, $\mathrm{pH}$, organic matter, water-holding capacity, nutrient content. In practice, these ideal spots are difficult to find. If there is no or inadequate reference information, effects can only be determined in relative terms by comparison with other sites. This is usually adequate for determining the degree of urgency and/or the need for remediation. Reference data can be 


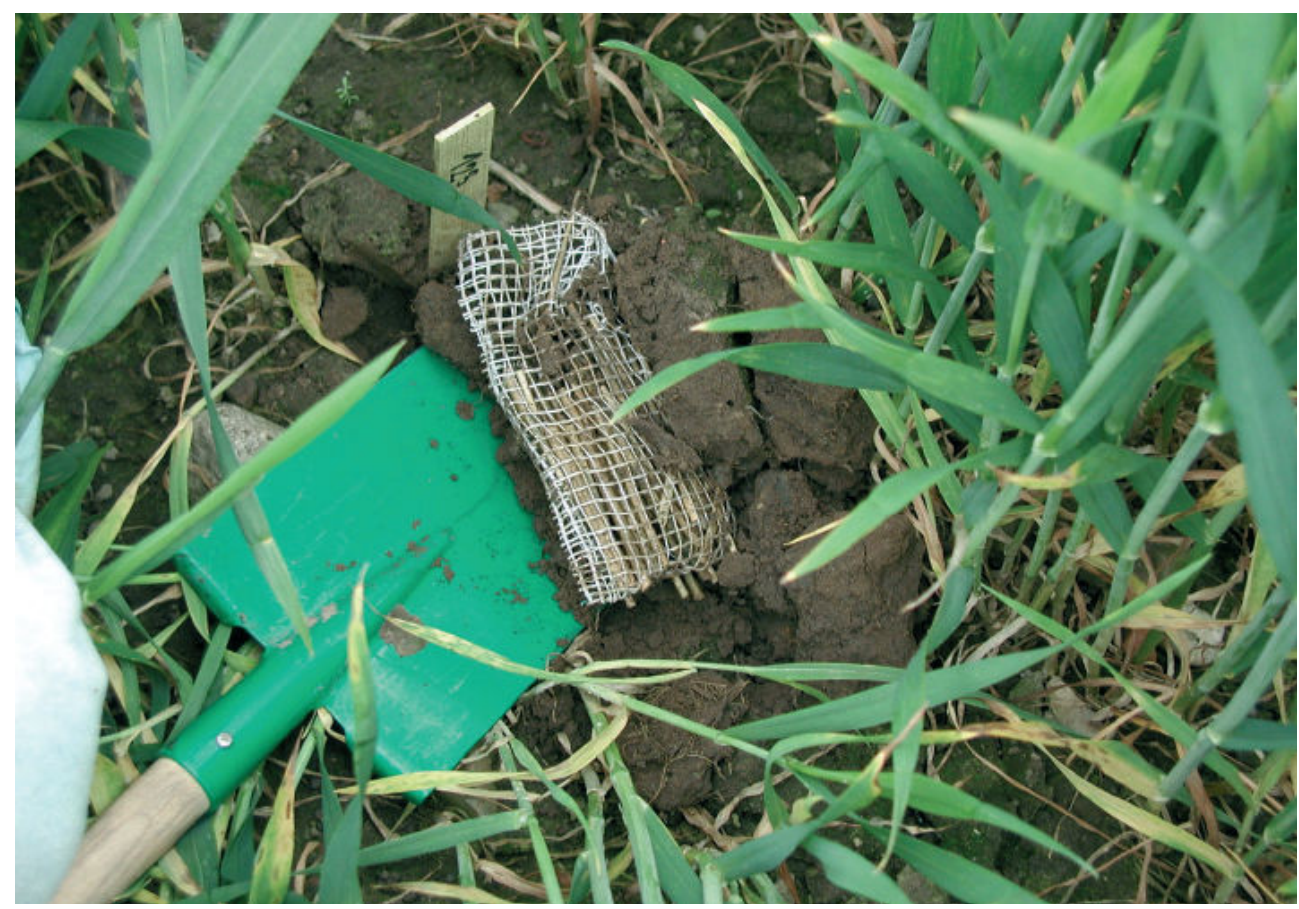

Figure 10. Litter bags [94]

obtained by including reference sites (preferably more than one) in the sampling scheme, including reference measurements in the experimental set-up, or by obtaining reference data from the literature or by expert based judgment.

Higher tier assessment of the impact on biological activity and organic matter breakdown

In addition to the general information about biological activity in soils generated in Tier 2 from the bait-lamina test, other, slightly more laborious, tests may give additional information about the overall biological activity in soil, e.g. wheat straw decomposition (litter bag test) and cotton strip degradation. A review paper from Van Gestel et al. (2003) concluded that while the baitlamina gave the best reflection of the biological activity of soil animals, e.g. earthworms, springtails and enchytraeids, the litter bag test and the cotton strip test are more indicative of the microbial activity in the soil [96]. Knacker et al. (2003) reviewed the usefulness of five different litter decomposition tests and concluded that the litter-bag test had distinct advantages over the others [97]. All of these simple tests only give insight into the overall activity in soils and the breakdown of organic material. They are hence most suitable on their own in cases of land-use with low sensitivity, e.g. industrial land. For land-uses where structural endpoints, e.g. biodiversity or specific species, are the target of protection other endpoint(s) should be monitored as well. 
Higher tier assessment of the impact on the microbial community

The number of microorganisms, especially bacteria, in soil is extremely large. They differ widely in their function and sensitivity to chemicals. Besides more classical (and simple) measures of the microbial community like total bacterial biomass, the number of colony forming units and substance induced respiration rate (SIR), more advanced methods for assessing the impact of contamination on soil microorganisms have recently been made available.

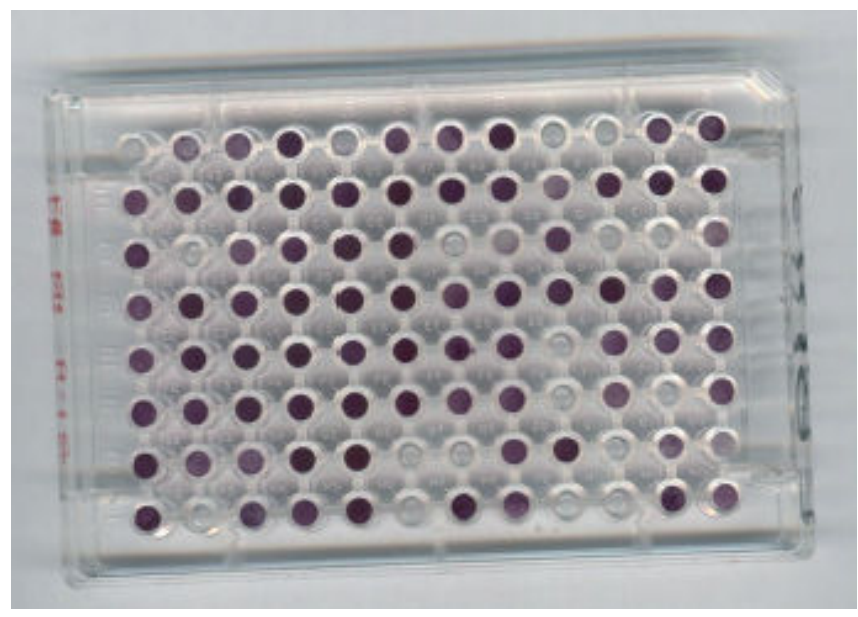

Figure 11. Microbial community [96]

This include microbial "fingerprinting" like phospholipid fatty acid analysis (PLFA) and community-level physiological-profiling (CLPP) based on metabolic response using BIOLOG plate systems, and the use of pollution induced community tolerance (PICT).

\section{Higher tier assessment of the impact on the plant community}

Plants interact dynamically with the physical and chemical characteristics of soils. Soil types and site characteristics, therefore, greatly influence the occurrence of plants and their total aboveground biomass (also called, Net Primary Production, i.e. NPP) within given climatic conditions and human management. Vegetation cover is an important indicator of soil quality and a diverse plant community is normally a good indication of essential soil functions such as the decomposition process, the mineralisation rate, and the occurrence of soil dwelling animals associated to (fresh) organic matter. Vascular plants are easy to sample. They are immobile and hence associated to soil contamination (and airborne pollution). Plant community parameters like plant cover, aboveground plant biomass, plant shoot/ root ratio, species diversity and the binary occurrence (presence/absence) of specific indicator species like metal-tolerant species may be used successfully in ERA. 


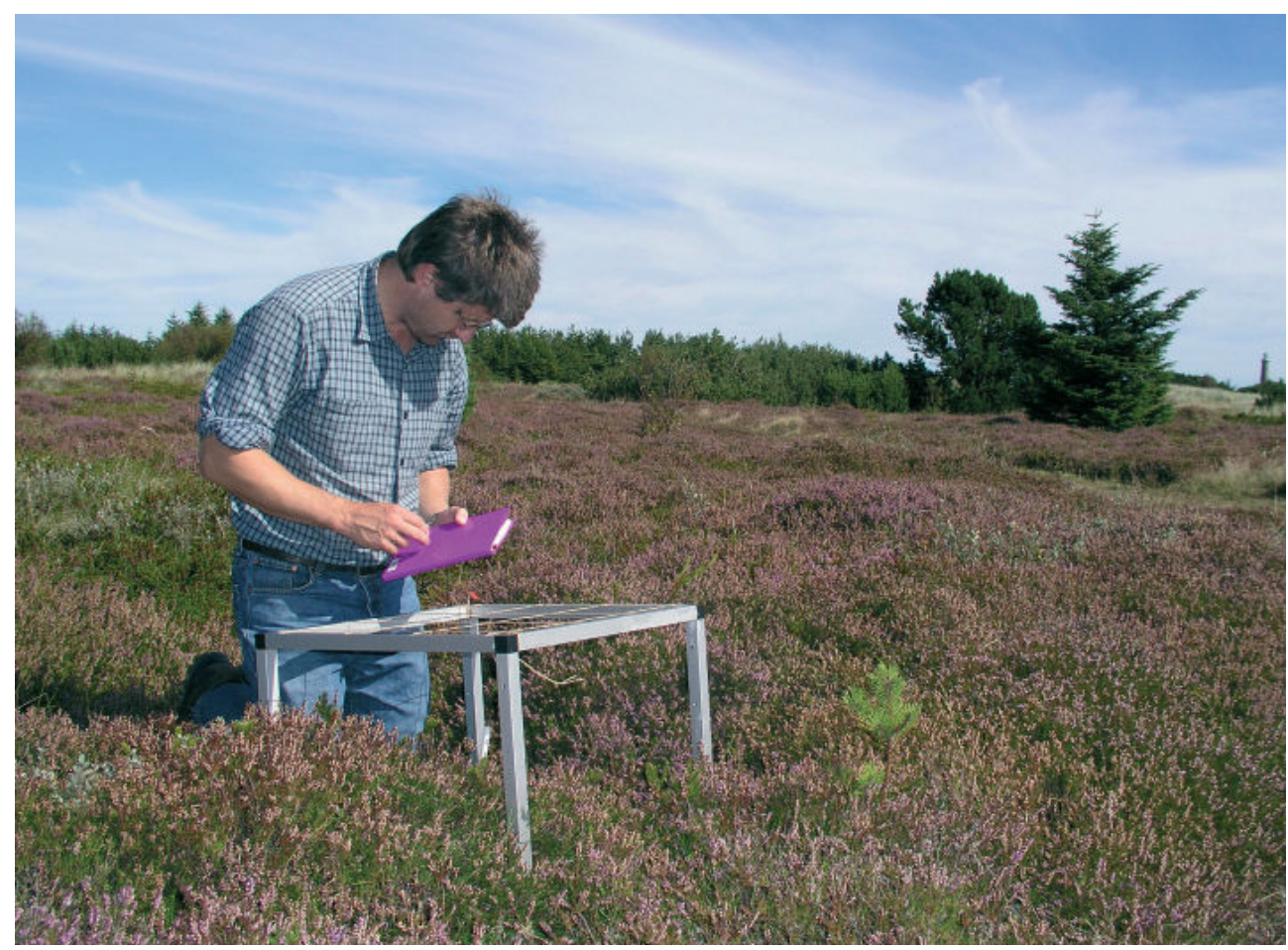

Figure 12. Plant survey [95]

Higher tier assessment of the impact on the soil invertebrate community

Survey of soil biota in order to evaluate the effect of various sources of pollution on soil communities on historically contaminated sites have not yet been used on a larger scale by e.g. consultants. However, numerous (monitoring) studies by various research groups can be found in the open literature. Methods of surveying include:

- Collection of soil samples followed by extraction in the laboratory.

- Extraction or collection of organisms in the field, e.g. by hand-sorting or by the application of mustard or formalin.

- Trapping (surface dwelling) animals by the use of e.g. pit-falls. Monitoring species includes earthworms, snails, oribatid mites, nematodes, springtails, ants, ground-living beetles and spiders. Most of the studies have been done on metal contaminated sites (see references below). A substantial amount of work has been put into the challenge of developing a soil invertebrate system for evaluating risk of pollutants. The only soil invertebrate system that is used on a regularly basis in the context of ecological risk assessment of contaminated soils is most likely the nematode Maturity Index (MI). The system is based on the evidence, that rapid colonising species dominate nematode communities in disturbed ecosystems. In the 
Netherlands experience with surveys of soil invertebrates from the monitoring programme Biological Indicator for Soil Quality (BISQ) has also been used in ERA..

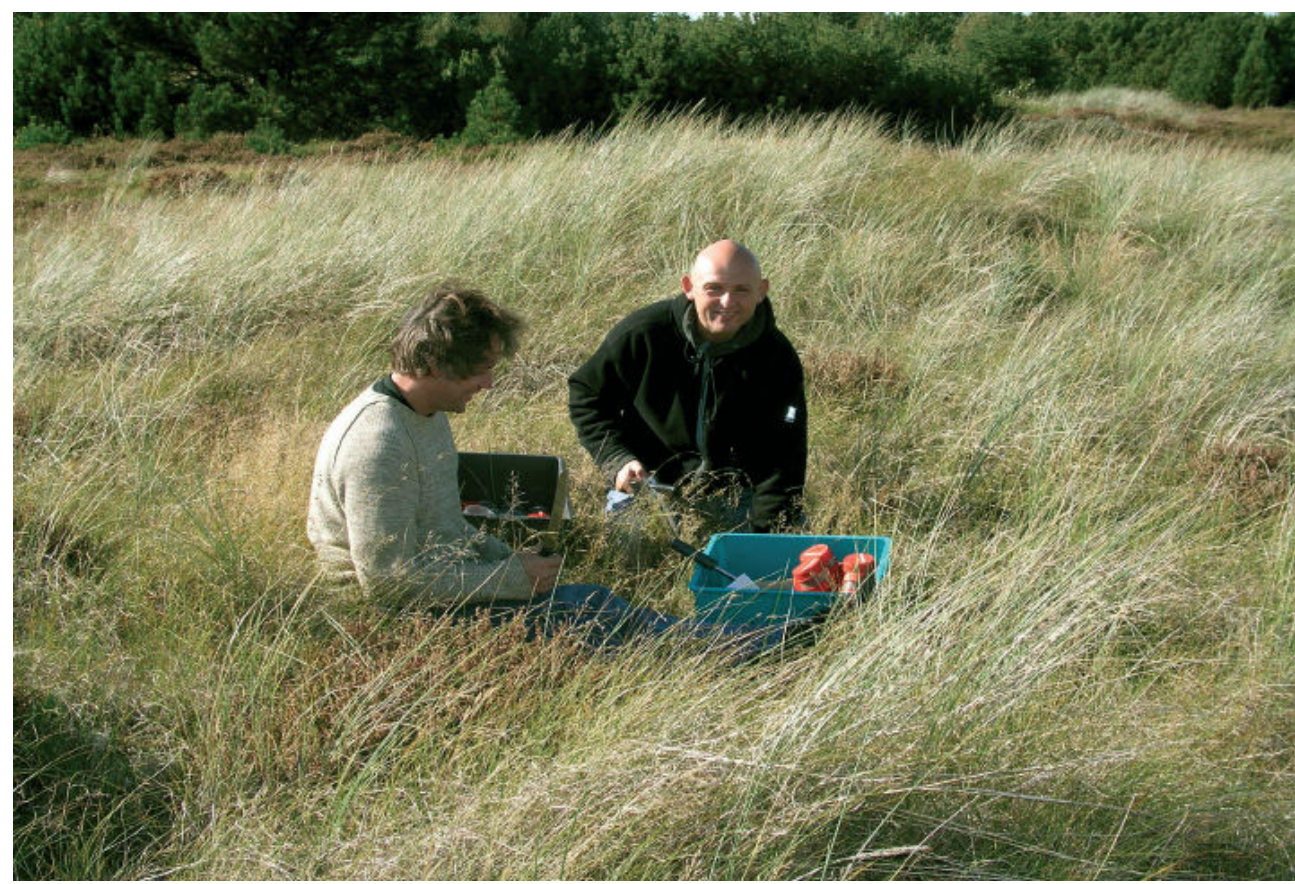

Figure 13. Soil fauna sampling [98]

\section{j. Toolbox for tests in Tier IV}

The final assessment in the ERA process is not likely to be initiated for many contaminated sites. The choice of additional tests or monitoring at this level of the ERA is bound to be very site-specific and hence an issue for negotiation between stakeholders and experts. Accumulation in biota is included in this toolbox as the internal concentration in biota is believed, at least to some extend, to reflect uptake and then bioavailability. An alternative in this final tier could also be to model uptake in biota provided sufficient data is available [98].

\section{Soil management program (Remediation)}

\subsection{Reporting norms and standards for contaminated land}

The aim is to investigate whether the land has been contaminated, and if contamination has occurred whether the contamination presents a significant risk of harm. The commonly encountered international practice consists of three distinct reporting phases. It progresses 


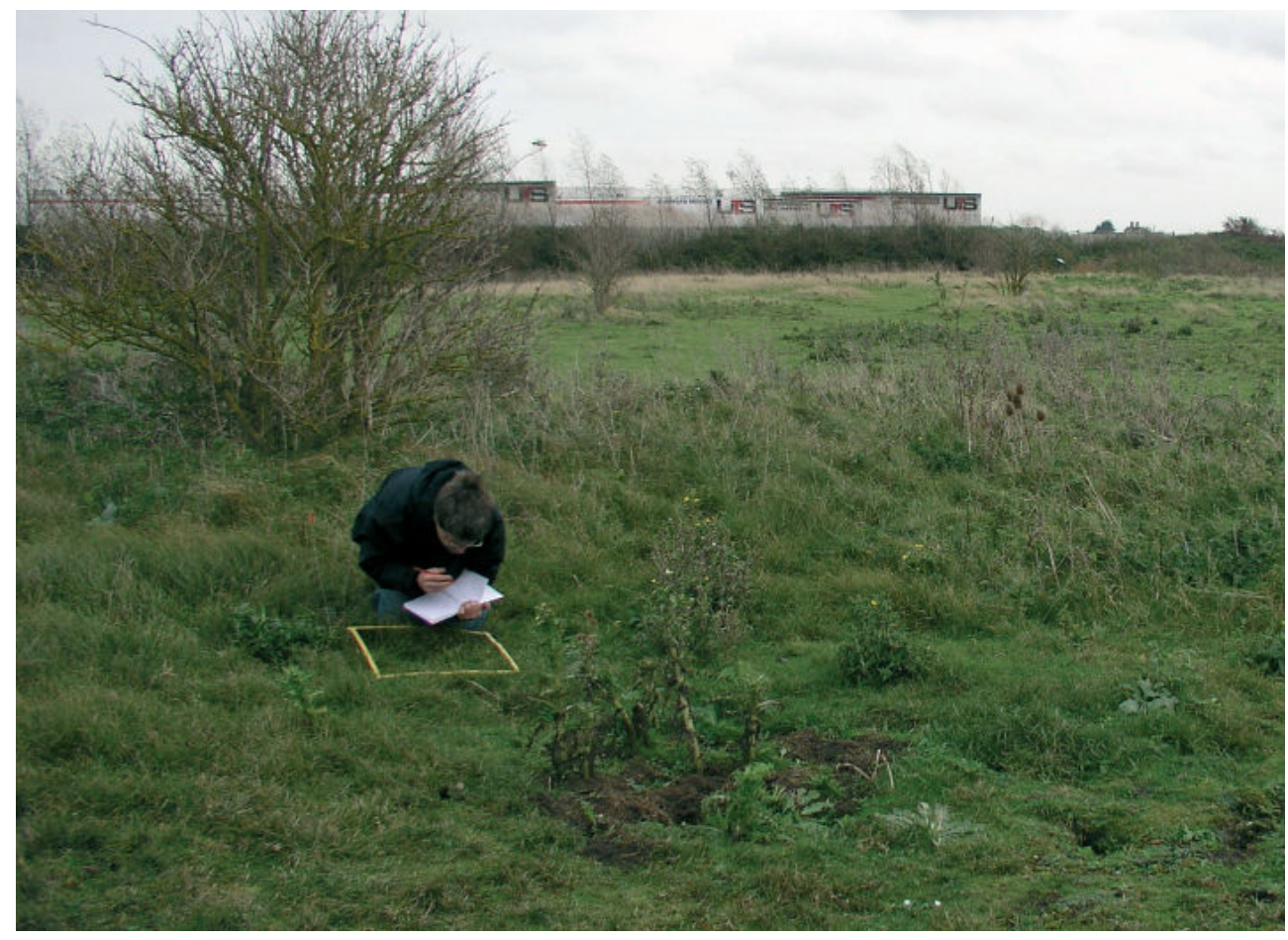

Figure 14. Detailed field survey [93]

from Phase 1 desktop and site walkover assessments with limited investigation and testing to a Phase 2 detailed invasive investigation and testing for site characterisation to a comprehensive Phase 3 report with an evaluation of remediation objectives and a proposed remediation plan, supported by control and monitoring measures for the activities.

The reporting system requires norms and standards of practice to be strictly applied, but also must retain flexibility to allow for decisions on the contaminated status of sites to be made in the most beneficial manner (considering ecological, social and economic aspects) also taking into account timeframes. In some cases, urgent priority works may require that the phased approach to reporting has to move forward in a concurrent single report.

\subsection{Requirements for preliminary site assessment phase 1}

A preliminary site assessment must consider the following elements

1. Site description-location and size

2. Nature and extent of contamination, contaminants of concern and historic activities that may be sources of contamination. List all present and past activities at the site that involves 


\section{Phase 1}

- Desktop Study

- Initial Investigations

- Preliminary Risk Assessment

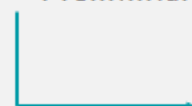

\section{Phase 2 - Site Assessment Report}

- Detailed Field Investigations

- Site Investigation Report

- Risk Quantification

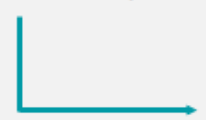

Phase 3

- Remediation Design and Implementation

- Control and Monitoring

- Long-Term Stewardship

Figure 15. A phase approach for the assessment and remediation of contaminated land

storage and production, use, treatment or disposal of hazardous material that could contaminate the site.

3. Describe current condition of the site and contents and the results of any previous assessment report

4. Local topography and geology, drainage, surface cover, vegetation.

5. Status of ground water, approximate depth to water table

6. Proximity to surface water

7. Proximity to drinking water supplies

8. Annual rainfall and flood potential

9. Land and water use for the nearby areas and site

10. Any other regulations as Regulated by the ministry

All data may not be available, or data may vary in terms of uncertainty, it is thus important to recognize gaps in the knowledge base and to decide whether additional data must be obtained 
on the site characterisation. This may trigger the commencement of Phase 2 Investigations. The Phase 1 report must make clear recommendations on the status of the contamination risk posed by the site. If a complete site history clearly demonstrates that the site activities do not pose a contamination threat then no further investigation is warranted and the site should be recommended as suitable for reuse. In most cases it is likely that some level of preliminary investigation will be required to provide the level of certainty required to enable property redevelopment or transfer. A limited investigation of certain subsurface activities, for example, underground storage tanks, would be necessary to obtain a waiver on the contamination status of a site at a Phase 1 level of reporting.

\subsection{Approval requirements}

If soil contaminants are found at concentrations that exceed the applicable standards specified in the approval, the approval holder is required to implement a soil management program.The program must first address source control to stop on-going contaminant releases. After the sources of contamination have been stopped, further assessment and delineation of the contaminated area may be necessary. When the extent of contamination is understood, remediation objectives, as described below, must be adopted for the area. Once remediation objectives have been agreed to, appropriate treatment or containment technologies can be chosen and the management plan finalized.

\subsection{Developing remediation objectives}

Remediation objectives may be developed in a variety of ways ranging from generic guidelines to site-specific risk assessment. Generic guidelines are numerical concentration limits that are applicable under a variety of site conditions. When neither Environmental Protection nor the agency has a guideline for a particular substance, four options are available. First, the remediation objective may be based on the ambient background concentration for the site. Second, the guideline development protocol may be applied. Third, a remediation objective may be adopted from another jurisdiction if the proponent can show that the remediation objective is consistent with the environmental protection goals of the approval. Finally, a remediation objective may be developed by the proponent using site-specific risk assessment procedures. A risk assessment for an approved facility will focus on human health concerns but fundamental ecological concerns must also be addressed. Site-specific risk assessment is a means of quantifying the likelihood that soil contamination will have a harmful effect under conditions found at a specific site. The essential components of human health and ecological risk assessments are similar; however, ecological risk assessments tend to be more complex than those for human health because a wide variety of receptors may have to be considered. Very briefly, a site-specific risk assessment may be described as consisting of the following steps or components as shown in Figure 20;

Problem formulation involves developing a conceptual model of the possible contaminant effects on receptors at the site. The conceptual model describes contaminant distribution and concentration in relation to the receptors and their patterns of activity on the site. The exposure assessment describes the pathways by which soil contaminants may be taken up by the receptor. 
This information is combined with receptor characteristics in order to estimate the contaminant uptake. The toxicity assessment describes the adverse effects that the contaminants may cause and the dose at which these effects occur.

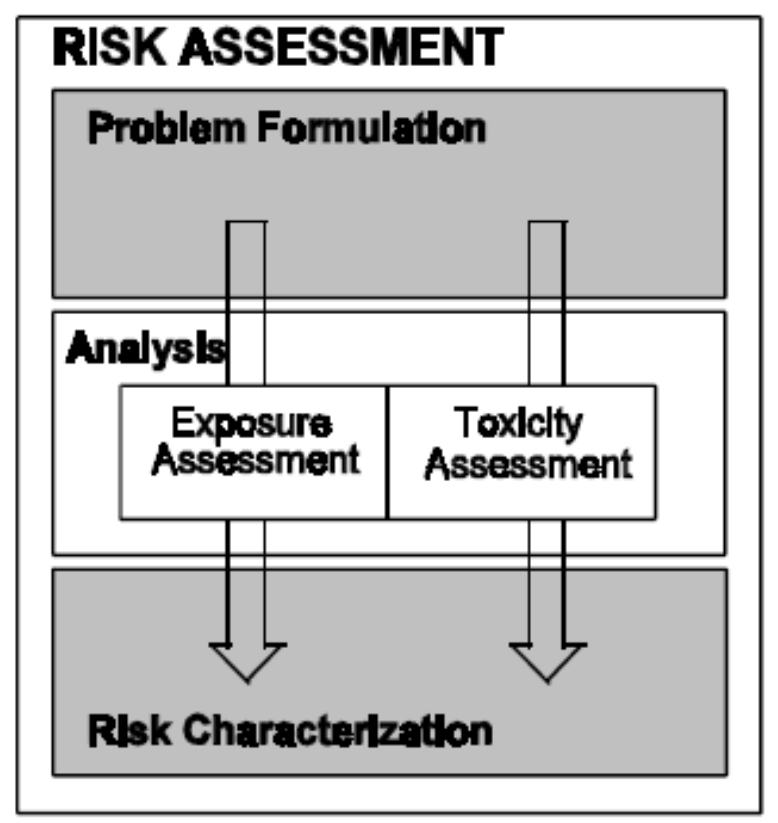

Figure 16. Risk Assessment Framework

The final step, risk characterization, compares this dose with the uptake rate (estimated during the exposure assessment) and determines whether or not an adverse effect is likely to occur. Risk assessment procedures can also be used to back calculate a contaminant concentration in soil at which no adverse effects are expected. At times, it may not be possible to remediate to a level compatible with industrial land-use objectives. In such cases, the approval holder must ensure that the contaminants are contained and receptor exposure does not occur. Formal risk assessment procedures are necessary to meet these requirements. Typically, an engineered containment system is required, the performance of which must be confirmed through periodic inspections and monitoring. The approval holder bears responsibility for the design, construction, assessment and maintenance of the risk management system, and any necessary emergency response should the system fail.

\subsection{Enforcement policy}

Enforcement is generally the last step in a regulatory process that aims to first prevent potential problems before they arise and to resolve existing problems in a cooperative manner. When 
discussions between the approval holder and the Department fail to prevent or resolve a contravention of an approval or the Act, a number of abatement and enforcement tools are available to the Department including:

- environmental protection orders;

- warning letters;

- tickets;

- administrative penalties;

- enforcement orders;

- prosecutions;

- court orders; and

- cancellation of approvals or certificates.

Due to various factors, including the high cost involved in remediation interventions, it is essential that a holistic and tiered, risk-based approach be adopted that is founded on international best practice, to address remediation in a uniform manner across the country. This is relevant irrespective of the sector of occurrence to safeguard both human health and the natural environment. The Framework is based on a review of international practice in the developed countries of the world and the emergence of remediation policy from developing countries, and an assessment of alternative approaches and methodologies that may find application in the development of a remediation framework.

\section{Conclusion}

Soil pollution is a result of many activities and experiments done by mankind which end up contaminating the soil. Industrial wastes such as harmful gases and chemicals, agricultural pesticides, fertilizers and insecticides are the most common causes of soil pollution. The others are ignorance towards soil management and related systems, unfavourable and harmful irrigation practices, improper septic system and management and maintenance of the same, leakages from sanitary sewage. There is urgent need for a tiered approach in ecological risk assessment of contaminated soils. Generic soil screening levels are needed as a first tier. Higher tiers of ecological risk assessment should, however, contain some kind of site-specific assessment. It is furthermore important to organize the various studies in a framework or decision support system that is transparent and useful for all stakeholders. A weight of evidence approach may be an obvious choice to deal with these uncertainties. The TRIAD approach, which incorporates and categorizes information in a triangle - chemistry, toxicology, and ecology - is an appropriate tool for handling conceptual uncertainties. Several remedies to these shortcomings have been proposed. Regarding ecotoxicity direct testing would allow for a major improvement in risk estimates. As to human health risks: including biological availability in 
risk estimates, more use of up to date knowledge about exposure routes, dose-effect relations and combination effects, and biomonitoring of effects are options for improvement.

\section{Acknowledgements}

Authors greatly acknowledge the University Malaya Research Grant (RG257-13AFR). Moreover, the comments of two anonymous reviewers are gratefully acknowledged.

\section{Author details}

Muhammad Aqeel Ashraf ${ }^{1}$, Mohd. Jamil Maah² and Ismail Yusoff ${ }^{1}$

1 Department of Geology, Faculty of Science, University of Malaya, Kuala Lumpur, Malaysia

2 Department of Chemistry, Faculty of Science, University of Malaya, Kuala Lumpur, Malaysia

\section{References}

[1] Okrent D. 1999. On intergenerational equity and its clash with intragenerational equity and on the need for policies to guide the regulation of disposal of wastes and other activities posing very long time risks. Risk Analysis 19: 877-901.

[2] Belluck, D.A., Benjamin, S.L., Baveye, P., Sampson, J., Johnson, B. 2003. Widespread arsenic contamination of soils in residential areas and public spaces: an emerging regulatory or medical crisis? International Journal of Toxicology 22: 109-128.

[3] Richardson, G.M., Bright, D.A., Dodd, M. 2006. Do current standards of practice in Canada measure what is relevant to human exposure at contaminated sites? II: oral bioaccessibility of contaminants in soil. Human and Ecological Risk Assessment 12: 606-618.

[4] Van Zorge, J. A. 1996. Exposure to mixtures of chemical substances: is there a need for regulations? Food and Chemical Toxicology 34, 1033-1036.

[5] Swartjes, F.A. 1999. Risk-based assessment of soil and groundwater quality in the Netherlands: standards and remediation urgency. Risk Analysis 19:1235-1248.

[6] Eikelboom, R.T., Ruwiel E., Goumans, J.J.M. 2001. The building materials decree: an example of a Dutch regulation based on the potential impact of materials on the environment. Waste Management 21: 295-302. 
[7] Crane, M. and Giddings, J.M. 2004. 'Ecologically acceptable concentrations' when assessing the environmental risks of pesticides under European Directive 91 414/EEC. Human and Ecological Risk Assessment 10: 733-747.

[8] Nathanail, P., McCaffrey, C., Earl, N., Forster, N.D., Gillett, A.G., Ogden, R. 2005. A deterministic method for deriving site-specific human health assessment criteria for contaminants in soil. Human and Ecological Risk Assessment 11: 389-410.

[9] Tarazona, J.V., Fernandez, M.D., Vega, M.M. 2005. Regulation of contaminated soils in Spain. Journal of Soil and Sediments 5:121-124.

[10] Evans, J., Wood, G., Miller, A. 2006. The risk assessment-policy gap: An example from the UK contaminated land regime. Environment International 32: 1066-1071.

[11] Huinink, J.T.M. 1998. Soil quality requirements of use in urban environments. Soil and Tillage Research 47: 157-162.

[12] Urzelai, A., Vega, M., Angulo, E. 2000. Deriving ecological risk-based soil quality values in the Basque Country. Science of the Total Environment 247: 279-284.

[13] Apitz, S.E. 2008. Is risk based, sustainable sediment management consistent with European policy. Journal of Soils and Sediments 8: 461-466.

[14] Provoost, J., Cornelis, C., Swartjes, F. 2006. Comparison of soil clean-up standards fort race elements between countries: why do they differ? Journal of Soil and Sediments 6: 173-181.

[15] Provoost, J., Reijnders, L., Swartjes, F., Bronders, J., Carlon, C., D'Allessandro, M., Cornelis, C. 2008. Parameters causing variation between soil screening values and the effect of harmonization. Journal of Soils and Sediments 8: 298-311.

[16] Toccalino, P.L. and Norman, J.E. 2006. Health-based screening levels to evaluate US Geological Survey groundwater quality data. Risk Analysis 26: 1339-1348.

[17] Patterson, M.M., Cohen, E., Prommer, H., Thomas, D.G., Rhodes, S., McKinley, A.I. 2007. Origin of mixed brominated ethane groundwater plume: contaminant degradation pathways and reactions. Environmental Science \& Technology 41: 1352-138.

[18] Leon Paumen, M. 2008. Invertebrate life cycle responses to PAC exposure. PhD thesis. Amsterdam: University of Amsterdam.

[19] Nawrot, T., Plusquin, M., Hogervorst, J., Roels, H.A., Celis, H., Thijs, L., Vangronsveld, J., Van Hecke, E., Staessen, J. 2006. Environmental exposure to cadmium and risk of cancer: a prospective population-based study. The Lancet Oncology 7: 119-126.

[20] Simcox, N.J., Fenske, R.A., Wolz, S.A., Lee, I.W., Kalman, D.A. 1995. Pesticides in household dust and soil: exposure pathways for children of agricultural families. Environmental Health Perspectives 103: 1126-1134.

[21] Laidlaw, M.A.S., Mielke, H.W., Filippelli, G.M., Johnson, D.L., Gonzales, C.R. 2005. Seasonality and children's blood lead levels: developing a predictive model using 
climate variables and blood data for Indianapolis, Indiana, Syracuse, New York and New Orleans Louisiana (USA). Environmental Health Perspectives 113: 793-800.

[22] Laidlaw, M.A.S., Mielke, H.W., Filippelli, G.M., Johnson, D.L. 2006. Blood lead in children: Laidlaw et al. respond. Environmental Health Perspectives 114: A 19.

[23] Rothenberg, S.J. and Rothenberg, J.C. 2005. Testing the dose-response specification in epidemiology: public health and policy consequences for lead. Environmental Health Perspectives 113: 1190-1195.

[24] Akesson, A., Lundh, T., Vahter, M., Bjellerup, P., Lidfeldt, J., Nerbrand, C., Samisoe, G., Strömberg, U., Skerfving, S. 2005. Tubular and glomerular kidney effects in Swedish women with low environmental cadmium exposure. Environmental Health Perspectives 113: 1627-1631.

[25] Nawrot, T.S., van Hecke, E., Thijs, L., Richart, T., Kuznetsova, T., Jin, Y., Vangronsveld, J., Roels, H.A., Staessen, J.A. 2008. Cadmium-related mortality and long-term secular trends in the cadmium body burden of an environmentally exposed population. Environmental Health Perspectives 116: 1620-1628.

[26] Lamphear, R.P., Dietrich, K., Auinger, P., Cox, C. 2000. Cognitive defects associated with blood lead concentrations, 10 microgram/dl in United States children and adolescents. Public Health Reports 115: 521-529.

[27] Wang, C.L., Chuang, H.J., Ho, C.K., Vang, C.Y. 2002. Relationship between blood lead concentrations and learning achievement among primary schoolchildren in Taiwan. Environmental Research A 89: 167-181.

[28] Wu, T., Buck, G.M., Mendola, P. 2003. Blood levels and sexual maturation in US girls. Environmental Health Perspectives 111: 737-741.

[29] Von Storch, H., Costa-Cabral, M., Hagner, C., Freser, F., Pacyna, Y., Pacyna, E., Kolb, S. 2003. Four decades of gasoline lead emissions and control policies in Europe: a retroactive assessment. Science of the Total Environment 311: 151-176.

[30] Mielke, H.W., Gonzales, C.R., Powell, E., Jartun, M., Mielke Jr., P.W.2007. Nonlinear association between soil lead and blood lead of children in Metropolitan New Orleans, Louisiana: 2000-2005. Science of the Total Environment 388: 43-53.

[31] Provoost, J., Cornelis, C., Swartjes, F. 2006. Comparison of soil clean-up standards for trace elements between countries: why do they differ? Journal of Soils and Sediments 6: 173-181.

[32] Miranda, M.L., Kim, D., Overstreet-Galeano, M.A., Paul, C.J., Hull, A.P., Morgan, S.P. 2007. The relationship between early childhood blood lead levels and performance on end-of-grade tests. Environmental Health Perspectives 115: 1242-1247.

[33] Patterson, B. M., Cohen, E., Prommer, H., Thomas, D. G., Rhodes, S., McKinley, A. J. 2007. Origin of a mixed brominated ethene groundwater plume: contaminant degradation pathways and reactions. Environmental Science \& Technology 41: 1352-1358. 
[34] Huel, G., Sahuquillo, J., Debotte, G., Oury, J., Takser, L. 2008. Hair mercury negatively correlates with calcium pump activity in human term newborns and their mothers at delivery. Environmental Health Perspectives 116: 263-267.

[35] Nawrot, T., Plusquin, M., Hogervorst, J., et al., 2006. Environmental exposure to cadmium and risk of cancer: a prospective population-based study. The Lancet Oncology 7: 119-126.

[36] Laidlaw, M. A. S., Mielke, H. W., Filippelli, G. M., Johnson, D. L. 2006. Blood lead in children: Laidlaw et al. respond. Environmental Health Perspectives 114: A19-A23.

[37] Akesson, A., Lundh, T., Vahter, M., et al., 2005. Tubular and glomerular kidney effects in Swedish women with low environmental cadmium exposure. Environmental Health Perspectives 113: 1627-1631.

[38] Mergler, D., Anderson, H.A., Chan, L.H.M., Mahaffey, K.R., Murray, M., Sakamoto, M., Stern, H.A. 2007. Methylmercury exposure and health effects in humans: a worldwide concern. Ambio 36: 3-11.

[39] ten Tusscher, G.W. 2002. Later childhood effects of perinatal exposure to background levels of dioxins in the Netherlands. PhD thesis. Amsterdam: University of Amsterdam.

[40] J. A. Van Zorge, "Exposure to mixtures of chemical substances: is there a need for regulations?"Food and Chemical Toxicology, vol. 34, no. 11-12, pp. 1033-1036, 1996.

[41] Filser, J., Koehler, H., Ruf, A., Rombke, J., Prinzing, A., Schaefer, M. 2008. Ecological theory meets soil ecotoxicology: challenge and chance. Basic and Applied Ecology 9: 346-355.

[42] Van Gestel, C.A.M. 2008. Physico-chemical; and biological parameters determine metal bioavailability in soils. Science of the Total Environment 406: 385-395.

[43] Sokolik, G.A., Ovsiannikova, S.V., Ivanova, T.G., Leinova, S.L. 2004. Soil-plant transfer of plutonium and americium in contaminated regions of Belarus after the Chernobyl catastrophe. Environment International 30: 939-947.

[44] Zhao, C., Ren, J., Xue, C., Lin, E., 2005. Study on the relationship between soil selenium and plant selenium uptake. Plant and Soil 277: 197-206.

[45] Liste, H., Prutz, I. 2006. Plant performance, dioxygenase-expressing rhizosphere bacteria, and biodegradation of weathered hydrocarbons in contaminated soil. Chemosphere 62: 1411-1420.

[46] van der Geest, H, Leon Paumen, M. 2008. Dynamics of metal availability and toxicity in historically polluted floodplain sediments. Science of the Total Environment 406: 419-425.

[47] Brouwer, A., Ahlborg, U.G., van den Berg, M., Birnbaum, L.S. 1995. Functional aspects of developmental toxicity of polyhalogenated hydrocarbons in experimental animals and human infants. European Journal of Pharmacology 293: 1-40. 
[48] Rutgers, M., Tuinstra, J., Spijker, J., Mesman, M., Wintersen, A., Posthuma, L. 2008. Risico's voor het ecosysteem in stap twee van het saneringscriterium [Ecosystem risks in step 2 of the remediation criterion]. Bilthoven (the Netherlands): RIVM.

[49] Li, J., Zhou, B., Liu, Y., Yang, Q., Cai, W. 2008. Influence of coexisting contaminants on bisphenol A sorption and desorption in soil. Journal of Hazardous Materials 151: 389-393.

[50] Gennings, C., Carter Jr, W.H., Casey, M., Moser, V., Carchman, R., Simmons, J.E. 2004. Analysis of functional effects of five pesticides using a ray design. Environmental Toxicology and Pharmacology 14: 115-126.

[51] Hayes, T.B, Case, P., Chui, S., Chung, D., Haeffele, C., Haston, K., Lee, M., Mai, V.P., Marjuoa, Y., Parker, J., Tsui, M. 2006. Pesticide mixtures, endocrine disruption and amphibian declines: are we underestimating the impact. Environmental Health Perspectives 114, Supplement 1: 40-50.

[52] Perry, M.J., Venners, S.A., Barr, D.B., Xu, X. 2007. Environmental pyrethoid and organophosphorous insecticide exposures and sperm concentration. Reproductive Toxicology 23: 113-118.

[53] Laetz, C.A., Baldwin, D.H., Clllier, T.K., Hebert, V., Stark, J.D., Scholz, N.L. 2009. The synergistic toxicity of pesticide mixtures: implications for risk assessment and the conservation of the endangered Pacific salmon. Environmental Health Perspectives 117: 348-353.

[54] Roos, P. H., Tschirbs, S., Pfeifer, F., et al., 2004. Risk potentials for humans of original and remediated PAH-contaminated soils: application of biomarkers of effect. Toxicology 205: 181-194.

[55] Xiao, R. Y., Wang, Z., Wang, C. X., Yu, G., Zhu, Y. G. 2006. Genotoxic risk identification of soil contamination at a major industrialized city in northeast China by a combination of in vitro and in vivo bioassays. Environmental Science \& Technology 40: 6170-6175.

[56] Lee, D. H., Lim, J. S., Song, K., Boo, Y., Jacobs Jr., D. R. 2006. Graded associations of blood lead and urinary cadmium concentrations with oxidative-stress-related markers in the U.S. population: results from the third National Health and Nutrition Examination Survey. Environmental Health Perspectives 114: 350-354.

[57] De Zwart, D. and Posthuma L. 2005. Complex mixture toxicity for single and multiple species: proposed methodologies. Environmental Toxicology and Chemistry 24: 2665-2676.

[58] Altenburger, R., Walter, H., Grote, M. 2004. What contributes to the combined effect of a complex mixture? Environmental Science \& Technology 38: 6353-6362.

[59] Filser, J., Wittmann, R., Lang A. 2000. Response types in Collembola towards copper in the microenvironment. Environmental Pollution 107: 71-78. 
[60] Drexler, J.W. and Brattin, J.W. 2007. An in vitro procedure for estimation of lead relative bioavailability: with validation. Human and Ecological Risk Assessment 13: 383-401.

[61] O'Halloran, K. 2006. Toxicological considerations of contaminants in the terrestrial environment for ecological risk assessment. Human and Ecological Risk Assessment 12: 74-83.

[62] Römbke, J. 2006. Tools and techniques for the assessment of ecotoxicological impacts of contaminants in the terrestrial environment. Human and Ecological Risk Assessment 12: 84-101.

[63] Roos, P.H., Tschirbs, S., Pfeifer, F., Welge, P., Hack, A., Wilhelm, M., Bolt, H.M. 2004. Risk potentials for humans of original and remediated $\mathrm{PAH}-$ contaminated soils: application of biomarkers of effect. Toxicology 205: 181-194.

[64] Xiao, R., Wang, Z., Wang, C., Yu, G., Zhu, Y. 2006. Genotoxic risk identification of soil contamination at a major industrialized city in north east China by a combination of in vitro and in vivo bioassays. Environmental Science \& Technology 40. 6170-6175.

[65] Lee, D., Lim, J., Song, K., Boo, Y., Jacobs, D.R. Jr. 2006. Graded associations of blood lead and urinary cadmium concentrations with oxidative- stress-related markers in the US population: Results of the Third National Health and Nutrition Examination Survey. Environmental Health Perspectives 114: 350-354.

[66] Neumann, H.G. 1996. Toxic equivalence factors, problems and limitations. Food and Chemical Toxicology 34: 1045-1051.

[67] Dobrev, I.D., Andersen, M.E., Yang, R.S.H. 2002. In silico toxicology: simulating interaction thresholds for human exposure to mixtures of trichloroethylene, tetrachloroethylene and 1,1,1 trichloroethane. Environmental Health Perspectives 110: 1031-1039.

[68] Silva, E., Rajapakse, N., Kortenkamp, A. 2002. Something from 'nothing'-eight weak estrogenic chemicals combined at concentrations below NOECs produce significant mixture effects. Environmental Science \& Technology 36: 1751-1756.

[69] Richter, M. and Escher, B. 2005. Mixture toxicity of reactive chemicals by using two bacterial growth assays as indicators of protein and DNA damage. Environmental Science \& Technology 39: 8753-8761.

[70] Caeiro, S., Costa, M. H., Ramos, T. B. 2005. Assessing heavy metal contamination in Sado Estuary sediment: An index analysis approach. Ecological Indicators 5: 151-169.

[71] Håkanson, L. 1980. An ecological risk index for aquatic pollution control: A sedimentological approach. Water Research 14: 975-1001.

[72] Long, E. R., MacDonald, D. D. 1998. Perspective: Recommended uses of empirically derived, sediment quality guidelines for marine and estuarine ecosystems. Human and Ecological Risk Assessment 4: 1019-1039. 
[73] Pekey, H., Karakaş, D., Ayberk, S., et al., 2004. Ecological risk assessment using trace elements from surface sediments of İzmit Bay (Northeastern Marmara Sea) Turkey. Marine Pollution Bulletin 48: 946-953.

[74] Roach, A. C. 2005. Assessment of metals in sediments from Lake Macquarie, New South Wales, Australia, using normalization models and sediment quality guidelines

[75] Sutherland, R. A. 2000. Bed sediment-associated trace metals in an urban stream, Oahu, Hawaii. Environmental Geology 39: 611-627

[76] Bhattacharya, A., Routh, J., Jacks, G., et al., 2006. Environmental assessment of abandoned mine tailings in Adak, Västerbotten District (Northern Sweden). Applied Geochemistry 21: 1760-1780

[77] Usero, J., González-Regalado, E., Gracia, I. 1996. Trace metals in the Bivalve Mollusc Chamelea Gallina from the Atlantic Coast of Southern Spain. Marine Pollution Bulletin 32: 305-310.

[78] Cheng, J. L., Shi, Z., Zhu, Y. W. 2007. Assessment and mapping of environmental quality in agricultural soils of Zhejiang Province, China. Journal of Environmental Sciences, 19: 50-54

[79] Reeves, W.R., Barhoumi, R., Burghardt, R.C., Lemke, S.J., Mayura, K., McDonald, T.J., Phillips, T.D., Donelly, K.C.2001. Evaluation of methods for predicting the toxicity of polyaromatic hydrocarbon mixtures. Environmental Science \& Technology 35: 1630-1636.

[80] El Masri, H., Mumtaz, M.M., Yushak, M.L. 2004. Application of physiologically-based pharmacokinetic modeling to investigate the toxicological interaction between chlorpyrifos and parathion in rat. Environmental Toxicology and Pharmacology 16: 5771.

[81] Kortenkamp, A. and Altenburger, R. 1999. Approaches to assessing combination effects of estrogenic environmental pollutants. Science of the Total Environment 333: 131-140.

[82] Sumpter, J.P. and Johnson, A.C. 2005. Lessons from endocrine disruption and their application to other issues concerning trace organics in the aquatic environment. Environmental Science \& Technology 39: 4321-4332.

[83] Brian, J.V, Harris, C.A., Scholze, M., Backhaus, T., Booy, P., Lamoree, M., Pojana, G., Jonkers, N., Runnalis, T., Bonfä, A., Marcomini, A., Sumpter, J. 2005. Accurate prediction of the response of freshwater fish to a mixture of estrogenic chemical. Environmental Health Perspectives 113: 721-728.

[84] Wölfe, D. 1997. Interactions between 2,3,7,8 TCDD and PCs as tumor promoters: limitations of TEFs. Teratogenesis, Carcinogenesis and Mutagenesis 17: 217-224.

[85] Marchant, C.A. 1996. Prediction of rodent carcinogenicity using the DEREK system for 30 chemicals currently being tested by the National Toxicology Program. Environmental Health Perspectives 104: 1065-1073. 
[86] Verhaar, H.J.M., Morroni, J.R., Reardon, K.F., Hays, S,M., Gaver, D.P., Carpenter, R.L., Yang, R.S.H. 1997. A proposed approach to study the toxicology of complex mixtures of petroleum products. Environmental Health Perspectives 195 (Supplement 1): 179-195.

[87] Stevenson, C.N., Macmanus-Spencer, L.A., Luckenbach, T., Luthy, R.C., Epel, D. 2006. New perspectives on perfluorochemical ecotoxicology: inhibition and induction of an efflux transporter in the marine mussel Mytilus californianus. Environmental Science \& Technology 40: 5580-5585.

[88] Bailer, A.J., Hughes, M.R., See, K., Noble, R., Schaefer, R. 2002. A pooled response strategy for combining multiple lines of evidence to quantitatively estimate impact. Human and Ecological Risk Assessment 8:1597-1612..

[89] Chapman, P.M., McDonald, B.G., Lawrence, G.S. 2002. Weight-of-evidence issues and frameworks for sediment quality (and other) assessments. Human and Ecological Risk Assessment 8:1489-1515.

[90] Rutgers, M., den Besten, P. 2005. Approaches to legislation in a global context.The Netherlands perspective - soil and sediment. In:Toxicity Testing Environmental. Thompson C, Wahhia K, Loibner AP (eds). Blackwell, CRC Press, Oxford, pp 269-289.

[91] Alexander, M. 1995. How toxic are toxic chemicals in soil? Environmental Science and Technology. 29:2713-2717.

[92] Alexander, M. 2000. Aging, bioavailability, and overestimation of risk from environmental pollutants. Environmental Science and Technology. 34:4259-4265.

[93] Callahan, C. A., Menzie, C. A., Burmaster, D. E.,Wilborn, D. C., Ernst, T. 1991 On-site methods for assssesing chemical impact on the soil environment using earthworms: a case study at the Baird and McGuire superfund site, Holbrook, Massachusetts. Environmental Toxicology and Chemistry. 10:817-826.

[94] Attrill, M. J., Depledge, M. H., 1997. Community and population indicators of ecosystem health: Targeting links between levels of biological organisation. Aquatic Toxicology 38:183-197.

[95] Keddy, C., Greene, J. C., Bonnell, M. A. 1994. A review of whole organism bioassays for assessing the quality of soil, freshwater sediment and freshwater in Canada. Scientific series no. 198. Environment Canada, Ottawa, Ontario, Canada.

[96] Van Gestel, C. A. M., Kruidenier, M., Berg, M. P. 2003. Suitability of wheat straw decomposition, cotton strip degradation and bait-lamina feeding tests to determine soil invertebrate activity. Biology and Fertility of Soils 37:115-123.

[97] Knacker, T., Förster, B., Römbke, J., Frampton, G.K. 2003. Assessing the effects of plant protection products on organic matter breakdown in arable fields-litter decomposition test systems. Soil Biology and Biochemistry 35:1269-1287. 
[98] Jager, T., Fleuren, R.H.L.J., Hogendoorn, E.A., De Korte, G. 2003. Elucidating the routes of exposure for organic chemicals in the earthworm, Eisenia andrei (Oligochaeta). Environmental Science and Technology 37:3399-3404. 